\title{
MANGUEZAL DO ITACORUBI (FLORIANÓPOLIS, SC): UMA REVISÃO DA DISPONIBILIDADE DE DADOS ECOLÓGICOS VISANDO O DIRECIONAMENTO DE NOVOS ESTUDOS
}

\author{
Matheus Hobold Sovernigo ${ }^{{ }^{*}}$ \\ ${ }^{1}$ Graduando em Ciências Biológicas, Centro de Ciências Biológicas, Universidade Federal de Santa Catarina. Campus Universitário - Trindade. \\ Florianópolis, Santa Catarina, Brasil. CEP: 88040-900. \\ * Endereço para correspondência: Rua Coronel Maurício Spalding de Souza 1010. Florianópolis, Santa Catarina, Brasil. CEP: 88035-110. \\ E-mail: sovernigo@gmail.com.
}

\section{RESUMO}

O Manguezal do Itacorubi encontra-se em tal proximidade a núcleos urbanos de Florianópolis, que vem sendo utilizado para atender ao processo de expansão urbana através de atividades, como descarga de esgoto e aterramento. Desde o fim da década de 1960, pesquisas têm caracterizado esse ambiente, estudando o espaço funcional do ecossistema, as comunidades vegetais, animais e microbiológicas, os processos físicos, químicos e biológicos, além do manejo e impactos sobre o ecossistema. No presente trabalho, foi efetuado um levantamento bibliográfico dos dados disponíveis relacionados à ecologia do Manguezal do Itacorubi, com o objetivo de identificar os estudos que existem e quais precisam ser feitos para resultar na melhor compreensão do ambiente para seu uso sustentável. Apesar da certa abundância de dados sobre alguns fatores bióticos, certos grupos bióticos representativos não foram estudados ou o foram de modo insuficiente, além de nem sempre o estudo ser atual. Quanto aos dados abióticos, embora haja boa disponibilidade de dados sobre as mais diversas variáveis, estão levemente defasados, podendo não refletir com precisão as mudanças ocorridas nos últimos anos devido ao grande incremento urbano, principalmente pela construção de um Shopping Center. Assim, o monitoramento temporal periódico de dados físicos, químicos e biológicos é de suma importância para avaliação do ambiente, fundamental para futuras propostas de conservação, manejo e educação ambiental acerca do Manguezal do Itacorubi e da bacia hidrográfica que o inclui.

Palavras-chave: Manguezais e marismas, levantamento de dados, fatores bióticos e abióticos, conservação, qualidade de água.

\begin{abstract}
THE MANGROVE SWAMP OF ITACORUBI, FLORIANOPOLIS, BRAZIL: A REVIEW OF THE AVAILABLE ECOLOGICAL DATA FOR DIRECTING NEW STUDIES. The mangrove of Itacorubi is so close to the city centre of Florianopolis, Brazil, that it is directly exploited by the expanding city, for example as repository of wastes and debris. Since the late 1960s the mangrove was the object of studies trying to characterize the local ecosystem, plant and animal biota, physicochemical and biological processes, and management strategies to minimize human impact. The present paper presents a bibliographic survey of the available ecological data on the mangrove swamp of Itacorubi, while appointing areas in need of further investigation. Although the local biota was relatively well studied, some representative living groups were overlooked, and the employed methods are often outdated. Local abiotic parameters were relatively well documented, but most available data is outdated and not reflecting later alterations deriving of urban expansion (eg. construction of a nearby shopping mall). Monitoring physical, chemical and biological parameters in the Itacorubi mangrove is paramount for building robust panorama of the local ecological conditions as to properly evaluate proposals for the conservation, management and ecological education at the mangrove and its hydrographic bay.
\end{abstract}

Keywords: Mangroves and salt marshes, biotic and abiotic data, conservation, data survey, water quality. 


\section{RESUMEN}

MANGLAR DE ITACORUBI (FLORIANÓPOLIS, SC): UNAREVISIÓN DE LADISPONIBILIDAD DE DATOS ECOLÓGICOS, BUSCANDO EL DIRECCIONAMIENTO DE NUEVOS ESTUDIOS. El Manglar de Itacorubi se encuentra en tal proximidad de los núcleos urbanos de Florianópolis, que ha sido usado para atender el proceso de expansión urbana a través de actividades, como descarga de alcantarillado y aterramiento. Desde finales de la década de 1960, diversas investigaciones han caracterizado este ambiente, estudiando el espacio funcional del ecosistema, las comunidades vegetales, animales y microbiológicas, los procesos físicos, químicos y biológicos, además del manejo e impactos sobre el ecosistema. En este trabajo, fue efectuado un levantamiento bibliográfico de los datos disponibles relacionados con la ecología del Manglar de Itacorubi, con el objetivo de identificar los estudios que existen y cuales deben realizarse para una mejor comprensión de este ambiente y su uso sostenible. A pesar de la cierta abundancia de datos sobre algunos factores bióticos, ciertos grupos representativos no fueron estudiados o fueron estudiados de modo insuficiente, además de que no siempre los estudios son actuales. En cuanto a los datos abióticos, aunque haya una buena disponibilidad de datos sobre las más diversas variables, estas presentan un leve desfase, pudiendo no reflejar con precisión los cambios ocurridos en los últimos años debido al gran incremento urbano, principalmente por la construcción de un centro comercial. De esta forma, el monitoreo temporal periódico de datos físicos, químicos y biológicos es de suma importancia para la evaluación de este ambiente, fundamental para futuras propuestas de conservación, manejo y educación ambiental acerca del Manglar de Itacorubi y de la cuenca hidrográfica que la cual hace parte.

Palabras clave: Manglares y marismas, levantamiento de datos, factores bióticos y abióticos, conservación, calidad del agua.

\section{INTRODUÇÃO}

A ocupação desordenada das populações humanas no litoral ao longo dos tempos tem causado o uso irracional das bacias de drenagem e estuários. O incremento no aporte de nutrientes para os corpos d'água, o que ocasiona eutrofização, entre outros problemas, vem promovendo alterações ecológicas, econômicas, sociais e na saúde pública (Tundisi 2003).

Florianópolis possui um enorme potencial turístico, devido principalmente às suas belezas naturais. Assim sendo, a cidade passou de 187.871 habitantes em 1980 para 402.346 em 2008, de acordo com o Instituto Brasileiro de Geografia e Estatística (IBGE 2008). Desde o passado, o crescimento desenfreado no espaço limitado da Ilha tem causado consequências desastrosas a seus ecossistemas, tal como o que ocorre na Bacia Hidrográfica do Itacorubi, que deságua no Manguezal do Itacorubi. Área de crescimento preferencial no século XX, já sofreu inúmeros aterros para a implantação e ampliação de estradas do Complexo Administrativo Regional do Itacorubi e de residências. Ainda hoje, essa bacia possui vários problemas a serem solucionados, como deficiências no sistema viário, poluição por esgotos domésticos e industriais, insuficiência nas coletas de lixo, rede de abastecimento público de qualidade dúbia, moradias irregulares em Áreas de Preservação Permanente em morros, alagamentos em áreas mais baixas, subaproveitamento de nascentes para abastecimento local, entre outros (PMF 2000). Sugestões de propostas de intervenção para resolver essas questões foram mencionadas por Collares et al. (2004), sendo que algumas dessas já foram colocadas em prática.

$\mathrm{Na}$ região estava instalada uma estação de transbordo - antigo lixão (1956-1989) -, em uma área de 4ha administrada pela Companhia de Melhoramento da Capital (COMCAP), onde ocorria proliferação de ratos e insetos, produção de mau cheiro e chorume, que contaminava o manguezal e os cursos d'água, bem como a fauna e flora de modo geral, além dos riscos de explosões devido aos gases produzidos pelo processo de fermentação de matéria orgânica ali depositada ao longo dos anos (Panitz \& Masutti 2000b, PMF 2000). O teor de metais pesados também era elevado, fato esse descoberto quando se iniciaram os primeiros estudos com fatores abióticos em 1979, pela Companhia Estadual de Tecnologia de Saneamento Ambiental de São Paulo (CETESB) (CETESB 1979). Ao redor da estação, observava- 
se a morte de grande quantidade de árvores adultas, principalmente Avicennia schaueriana Stapf \& Leechman ex Moldenke, 1939. Assim, grandes clareiras eram formadas, descaracterizando o ambiente e dificultando a recuperação natural do manguezal (Cunha 2000). No entanto, a partir de 2000, esse cenário tem sido modificado com a inauguração do Centro de Transferência de Resíduos Sólidos (CTReS), um moderno sistema de manejo limpo dos resíduos sólidos, que conta com uma nova estação de transbordo, um centro de triagem para reciclagem, posto de lavagem da frota com tratamento da água e centro de capacitação e educação ambiental para funcionários, estudantes e comunidade em geral (COMCAP 2003), além do reflorestamento das áreas fronteiriças ao manguezal, propiciando a regeneração do mesmo (Oliveira \& Panitz 2003).

Em função da retificação dos rios Itacorubi e Sertão e a abertura de canais de drenagem pluvial paralelamente à Avenida Beira-Mar Norte no manguezal pelo extinto DNOS (Departamento Nacional de Obras e Saneamento), visando resolver os problemas da ocorrência de áreas consideradas insalubres e das enchentes nos bairros adjacentes, muitas alterações foram produzidas nos meandros dos canais naturais, ocasionando modificações nos padrões de circulação do ecossistema e morte de parte da vegetação (Ayala 2004, Vieira 2007).

OManguezal do Itacorubié, desde 1969, fiscalizado e gerido pela Universidade Federal de Santa Catarina (UFSC), que o utilizava apenas como área de campo para pesquisas científicas e para despejo de seus efluentes, embora essa última prática esteja hoje em desuso (Vieira 2007). Uma destas áreas para pesquisa resultou na supressão da vegetação deste ecossistema em aproximadamente 10ha, utilizados para formação dos tanques de carcinicultura pelos pesquisadores do Centro de Ciências Agrárias da UFSC, após a inauguração da Estação Experimental de Aquicultura do Itacorubi em 1979. Atualmente, os tanques estão desativados. Apenas em 1996, com a criação, na UFSC, da Coordenadoria de Gestão Ambiental (CGA 2006), a instituição passou a desenvolver ações de controle dos efluentes e resíduos sólidos gerados no Campus Universitário, bem como a executar programas ambientais.

Outra instituição que causa um impacto direto no manguezal é a Universidade do Estado de Santa Catarina (UDESC). De acordo com Souza \&
Napoleão (2002), além da supressão da vegetação original para a utilização da área ocupada por seus prédios à beira do manguezal, ocorre ainda a emissão de seus efluentes em um canal que passa à frente da instituição e desemboca no Rio Itacorubi. O conteúdo desses efluentes é tanto sanitário, com uma quantidade de coliformes totais e fecais extremamente alta (até 320 vezes mais alta que o permitido, em certos pontos), quanto rico em metais pesados, devido às tintas utilizadas nos laboratórios.

No final de 1999, foi inaugurado o elevado Vilson Kleinübing (Elevado do CIC), necessário para atender a demanda viária crescente na Ilha. A construção reduziu em 1,3ha a área do manguezal adjacente, devido ao aterramento para fins do empreendimento (Oliveira \& Panitz 2003). Por isso, foram tomadas algumas medidas para reduzir o impacto, como a instalação de tecidos para prevenir o soterramento dos pneumatóforos pelos materiais resultantes da construção e o resgate e realocação de 2004 indivíduos de espécies típicas de mangue e cerca de 300 caranguejos de diferentes espécies (Porto-Filho \& Panitz 2000).

O primeiro Plano de Gestão da Unidade foi publicado em 2000 (Zanchet 1998). O documento foi utilizado como reforço para a criação do Parque Municipal do Manguezal do Itacorubi, dois anos depois, através do Decreto Municipal 1529/2002 (PMF 2002), onde ficou estabelecido que a gestão do Parque fosse compartilhada entre a UFSC e a PMF. Esse documento definiu o Parque como tendo 150ha de área de manguezal (Panitz 1997a). Na implantação do primeiro plano de manejo, referente à infraestrutura, apenas algumas trilhas foram executadas após a criação do Parque, sustentadas por andaimes de madeira, que possibilitavam o contato direto com as espécies do mangue e a observação da fauna, sendo que hoje em dia uma delas se encontra destruída. Gonzalez (2004) forneceu dados para um programa de educação ambiental para o Parque, referente à criação de material visual educativo, trilhas por água, oficinas ecológicas, aquário e viveiro. São objetivos viáveis, visto que, devido à construção do Shopping Center Iguatemi em 2007, algumas das medidas compensatórias acordadas na Licença Ambiental de Implantação e na Licença Ambiental de Projeto seriam a implantação definitiva da parte física e operacional e a manutenção do Parque Municipal do Manguezal do Itacorubi. A construção desse Shopping 
Center originou um embate entre diversos setores da sociedade a respeito do modo como foi licenciado. Todos os trâmites legais desse processo podem ser conferidos em amplo trabalho de Pontes (2007).

A partir de 2006, a comunidade residente na Bacia Hidrográfica do rio Itacorubi encontrou-se envolvida na elaboração do novo Plano Diretor do município de Florianópolis, representada pelo conjunto de moradores presentes nas assembléias e membros dos conselhos comunitários dos loteamentos e bairros do entorno, através da União dos Conselhos Comunitários da Bacia do Rio Itacorubi (UNICOBI) (Unicobi 2006).

A Organização Não Governamental (ONG) Aliança Nativa (Aliança Nativa 2009) vem atuando nos últimos anos através de parcerias entre a sociedade civil e os poderes público e privado, no intuito de resolver o problema do acúmulo excessivo de lixo sólido no mangue do Itacorubi. Além disso, ela tem incentivado projetos de pesquisa, como "Monitoramento, Estimativa de Biomassa e Quantificação de Incorporação de $\mathrm{CO}_{2}$ " e "Recuperação de Área Degradada (Antigo Lixão do Itacorubi), Tratamento de Resíduo Líquido (Chorume) em área selecionada - Fitorremediação", que tem como finalidade a recuperação e conservação do Manguezal do Itacorubi.

Há algumas décadas, a biota do manguezal tem sido estudada, tanto por pesquisadores da UFSC quanto outros. De bactérias, protistas, algas e fungos, aos vegetais superiores, invertebrados e vertebrados. Alguns grupos de importância fundamental ao manguezal ainda não foram pesquisados, como os répteis, por exemplo. A relação desses seres vivos com os fatores abióticos, como a presença e quantidade de íons, elementos e moléculas, além dos fatores climáticos, é apresentada a todo o momento, de forma a esclarecer todos os aspectos ecológicos estudados ou não do Manguezal do Itacorubi.
Oobjetivo deste trabalho foi realizar uma revisão de dados, a mais completa possível, em relação à ecologia do Manguezal do Itacorubi. Com as informações levantadas, pretendeu-se sugerir os estudos que devem ser realizados, a fim de compreender a dinâmica do manguezal e sua biodiversidade. Essas informações são essenciais para futuros planos de conservação do Manguezal do Itacorubi e de sua bacia hidrográfica.

\section{MATERIAL E MÉTODOS}

\section{ÁREA DE ESTUDO}

O Manguezal do Itacorubi (Figura 1), um manguezal do tipo bosque misto de bacia (SorianoSierra et al. 1998b), situado entre as coordenadas

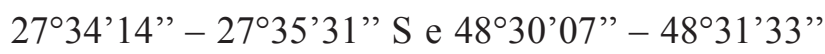
$\mathrm{W}$, encontra-se no setor Centro-Oeste da Ilha de Santa Catarina, SC, Brasil, na área estuarina da Bacia Hidrográfica do Itacorubi, que possui 2844,6ha de acordo com Vieira (2007), e é alimentado pelos rios Itacorubi e Sertão, com extensões totais de $8,1 \mathrm{~km}$ e $5,9 \mathrm{~km}$, sendo que desse total, respectivamente, $3,27 \mathrm{~km}$ e $2,2 \mathrm{~km}$ estão dentro da área do manguezal (Dutra 1994, Sánchez Dalotto 2003). Em contato com o perímetro do manguezal estão presentes os bairros João Paulo, Itacorubi, Santa Mônica, Trindade e Agronômica, além da Baía Norte. Maiores detalhes da Bacia Hidrográfica do Itacorubi, anteriormente chamada de Bacia Hidrográfica do Córrego Grande, podem ser conferidos em Dutra $(1994,1998)$.

Há muita controvérsia quanto à área total do Manguezal do Itacorubi (Tabela I). A maioria dos trabalhos reunidos nessa revisão refere-se à área de 142ha, definida por Soriano-Sierra (1993), e à área de 150ha, definida por Panitz (1997a); no entanto, esses trabalhos não são os mais atuais. O que há em concordância entre os autores é que o manguezal diminuiu em muito sua área desde 1938, data da primeira cobertura aérea.

Tabela I. Medidas da área total (ha) do Manguezal do Itacorubi em diferentes anos, por diversos autores. Autor *: ${ }^{1}$ Nascimento (1989), ${ }^{2}$ Ayala (2004),

${ }^{3}$ Soriano-Sierra et al. (1998b), ${ }^{4}$ Panitz (1993), ${ }^{5}$ Soriano-Sierra (1993), ${ }^{6}$ Oliveira \& Panitz (2003), ${ }^{7}$ Panitz (1997a), ${ }^{8}$ Sánchez Dalotto (2003).

Table I. Measures of the total area (ha) of the mangrove swamp of Itacorubi as taken by different authors in different years. *: ${ }^{1}$ Nascimento (1989), ${ }^{2}$ Ayala (2004), ${ }^{3}$ Soriano-Sierra et al. (1998b), ${ }^{4}$ Panitz (1993), ${ }^{5}$ Soriano-Sierra (1993), 6 Oliveira \& Panitz (2003), ${ }^{7}$ Panitz (1997a),

${ }^{8}$ Sánchez Dalotto (2003).

\begin{tabular}{cccccccccccccccc}
\hline Ano & 1938 & 1956 & 1957 & 1966 & 1969 & 1978 & 1984 & 1990 & 1993 & 1994 & 1997 & 1998 & 1999 & 2002 \\
\hline \multirow{2}{*}{ Área } & $253 ;$ & 215 & 220 & 200 & 198 & $\begin{array}{c}226,4 ; \\
173\end{array}$ & 162 & 155 & 142 & 192,$6 ;$ & 176,6 & 150 & 182,9 & 180 & 178,1 \\
& 211 & & & 2 & 1 & 2 & $2 ; 1$ & 3 & 4 & 5 & $2 ; 6$ & 7 & 2 & 8 & 6 \\
\hline
\end{tabular}



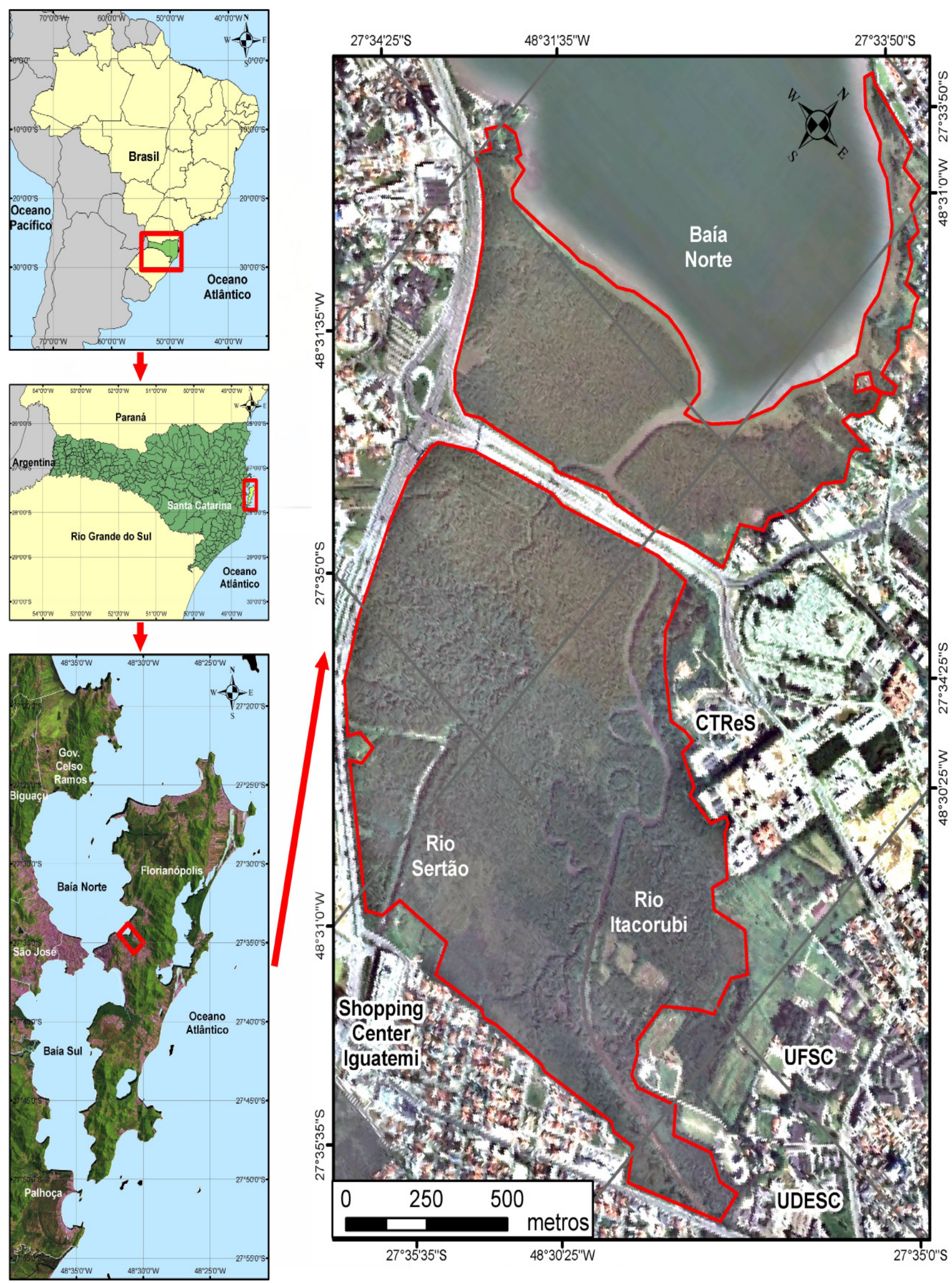

Figura 1. Contextualização do Manguezal do Itacorubi (área em vermelho), a nível continental, federal, estadual e municipal. Georreferenciado e vetorizado pelo autor a partir de bases cartográficas digitais do IBGE e fotografias de satélites Landsat 7 e Google (imagens cedidas pela Eletrosul Centrais Elétricas S.A.).

Figure 1. Geographical location of the mangrove swamp of Itacorubi (shown in red). Georeferenced and vectorized from cartographic information from $I B G E$ and based on aerial imagery from Landsat 7 and GoogleEarth (images gently provided by Eletrosul Eletricas SA). 


\section{LEVANTAMENTO DE DADOS}

No presente trabalho, foram realizadas pesquisas bibliográficas utilizando a palavra-chave "Itacorubi". Todos os trabalhos em português, inglês, espanhol e francês, encontrados com esse parâmetro, seja no título, resumo ou corpo do texto, foram analisados. Porém, foram considerados apenas os que continham dados ecológicos sobre o Manguezal do Itacorubi. As fontes de referência foram extraídas dos bancos de dados Pergamum das Bibliotecas Universitárias da Universidade Federal de Santa Catarina e da Universidade do Estado de Santa Catarina, onde foram pesquisados livros, monografias, dissertações e teses. Além disso, realizaram-se buscas na Sala de Leitura de Biologia da UFSC, onde foram pesquisados trabalhos de conclusão de curso, e nas seguintes bases de dados: Sistema Scopus, Sistema Web of Science, Portal Scielo e Google Acadêmico.

\section{RESULTADOS E DISCUSSÃO}

\section{FATORES ABIÓTICOS}

Em 1979, a CETESB realizou o primeiro estudo sobre o impacto do aterro de lixo no Manguezal do Itacorubi (CETESB 1979). Naquela época, alguns metais, como cromo, mercúrio e ferro, se encontravam em concentrações permitidas pela legislação vigente, enquanto que o manganês estava acima desse limite. Após a desativação do lixão, em 1989, continuaram os estudos. As concentrações de metais em compartimentos bióticos (Spartina alterniflora Loiseleur, 1987, Chasmagnathus granulata Dana, 1851 e Mytella guyanensis Lamarck, 1819) e abióticos (água intersticial e sedimento) foram determinadas para que se avaliasse a qualidade ambiental e a função do manguezal como barreira biogeoquímica ao aporte de metais de origem antropogênica (Masutti \& Panitz 1999). Os resultados indicaram que o ecossistema estava moderadamente poluído, sobretudo por cobre e cádmio. Masutti \& Panitz (1999) também sugeriram que a principal fonte de metais pesados era o aterro de lixo do Itacorubi.

Queiroz et al. (1998a) analisaram amostras de água e sedimentos por fluorescência $X$ e espectrofotometria de absorção atômica. Constataram a poluição por cádmio, níquel, ferro e alumínio nos compartimentos abióticos do Manguezal, o que demonstrou a eficiência deste como barreira biogeoquímica seletiva na retenção dos metais pesados. Porém, a qualidade da água para o desenvolvimento da biota aquática estaria comprometida devido ao elevado conteúdo de ferro e alumínio. Já Moraes et al. (1998) analisaram as concentrações de ferro II e ferro III em diversos pontos do manguezal. Encontraram alto teor de ferro II em áreas próximas ao aterro sanitário, assim concluíram que o Manguezal do Rio Itacorubi encontrava-se redutor. Além disso, um alto teor de ferro III foi encontrado junto à Baía Norte, indicando trocas entre o manguezal e o oceano.

A acumulação e magnificação biológica foi medida por Sierra de Ledo et al. (1998). Foi detectada maior retenção de cádmio pelo mexilhão (M. guyanensis) e uma pequena quantidade de níquel pela tainha (Mugil platanus Günther, 1880), possível exportadora do poluente. Além disso, detectou-se concentração três vezes maior de níquel no caranguejo herbívoro $(C$. granulata) em relação a sua fonte alimentar capimpraturá (S. alterniflora), evidenciando o processo de magnificação ao longo da teia trófica. Constam também outros trabalhos sobre metais pesados no Manguezal do Itacorubi: Biodisponibilidade e bioconcentração de metais-traço (Masutti et al. 2000), Contribuição de S. alterniflora e C. granulata à ciclagem de metais (Masutti \& Panitz 2000), Contribuição, variação temporal e bioacumulação de metais pesados em $S$. alterniflora no manguezal do Itacorubi (Panitz \& Masutti 2000a), Variação temporal no teor de metais-traço e contribuição anual da biomassa de $S$. alterniflora à ciclagem de metais (Panitz \& Masutti 2000c) e Contaminação por metais presentes em sedimentos de superfície (Rivail da Silva et al. 1998). Neste último, foi encontrada alta concentração de mercúrio em um dos sítios do Manguezal do Itacorubi. Outro estudo definiu que as maiores quantidades de alumínio, cádmio e níquel estavam associadas aos sedimentos, enquanto que o ferro ocorria predominantemente na forma dissolvida na água, ambos com maior ocorrência dentro do manguezal do que na área costeira adjacente (Queiroz et al. 1998b).

Já em outras pesquisas, Masutti et al. (1998), por meio de estudos com glândulas digestivas de $M$. guyanensis, assim como Tribes et al. (1998), Wilhelm Filho et al. (2000) e Torres et al. (2002), detectaram 
um estresse oxidativo relacionado à presença de diversos metais-traço $(\mathrm{Cd}, \mathrm{Cr}, \mathrm{Pb}, \mathrm{Cu})$ muito acima do permitido para o consumo humano nos dois rios que deságuam no manguezal, sobretudo no rio Itacorubi. Pagliosa (2004) afirmou que as concentrações de cobre continuavam elevadas em todo o rio Itacorubi, principalmente na região mais interna. As atividades de remobilização dos sedimentos para alterações nas margens dos rios pareciam ser as principais responsáveis pelas altas concentrações desse metal no rio, uma vez que poderiam estar redisponibilizando o cobre anteriormente depositado. Esse estudo registrou também uma alta concentração de chumbo no sedimento do rio Itacorubi, normalmente associado à poluição atmosférica e à combustão em motores de explosão.

Não era sabido se a matéria nutritiva produzida pelos manguezais era exportada para os corpos de água adjacentes e incorporada nas cadeias tróficas (Rezende 1988 apud De La Corte 1995). Por isso, as taxas de importação e exportação de sêston, clorofila-a, feofitina-a, carbono orgânico, e enxofre foram mensuradas nas águas de fluxo (entrada) e refluxo (saída) da maré, com o objetivo de elucidar a função ecológica do manguezal para o enriquecimento da Baía Norte da Ilha de Santa Catarina em matéria orgânica e inorgânica, dissolvida e particulada, que pode ser utilizada pelos seres vivos que ocorrem nesse ambiente e que fazem parte de atividades econômicas, como a pesca e a maricultura (De La Corte 1995). Durante o fluxo e o refluxo de maré foram observadas altas concentrações de material particulado. A alta concentração de sêston apresentada no refluxo da maré estava relacionada com a intensa produção de detrito pelas macrófitas do manguezal por todo ano. A sua elevada concentração durante o fluxo era provavelmente devido à elevada taxa de decomposição de matéria orgânica presente nos bancos de Spartina, localizados na parte frontal do manguezal, o que foi corroborado por Panitz (1992). No balanço das campanhas, a média do sêston apresentou valores estatisticamente maiores em águas de refluxo, ou seja, havia mais exportação do que importação de matéria orgânica para a Baía Norte. Os resultados para a feofitina-a foram semelhantes, em decorrência da alta taxa de decomposição da matéria orgânica. Já para a clorofila-a, os resultados indicaram que provavelmente o manguezal apresentava produtividade primária fitoplanctônica inferior que a da Baía Norte. E, em relação ao carbono orgânico e enxofre, havia maior exportação do que importação, também verificado em outros estudos (Dankers et al. 1984 apud De La Corte 1995, Soriano-Sierra 1992 apud De La Corte 1995).

Os principais tensores atuantes no manguezal foram estudados por Panitz (1997b) e Oliveira \& Panitz (2003), que indicaram que a maior contribuição têm sido dos materiais de origem humana descarregados principalmente nos canais, além da construção destes, que deságuam no manguezal e têm provocado o soterramento dos pneumatóforos das espécies de mangue, além de criar barreiras contra a circulação da água no manguezal, essencial para sua manutenção. Apesar da ação dos tensores, tanto os antropogênicos quanto os naturais, devido a sua localização geográfica, as fontes de energia auxiliar asseguram o desenvolvimento com êxito da vegetação típica (Sierra de Ledo \& Soriano-Sierra 1998b).

A respeito do relevo do solo e da estrutura dos sedimentos, Soriano-Sierra et al. (1998b) definiram que o relevo do solo era quase horizontal, com altura máxima de $45 \mathrm{~cm}$ acima do nível médio da maré nas partes não modificadas pelo homem, como aterros e canais. O solo pardo-cinzento era constituído por silte e argila, com areia fina nos locais mais elevados. A concentração de matéria orgânica era muito variável, desde $1,2 \%$ na porção meso-inferior do rio Sertão a $18,7 \%$ na região medial entre os dois rios.

Sierra de Ledo \& Soriano-Sierra (1998b) fizeram um levantamento dos fatores mesoclimáticos de um período de 50 anos (1944-1993), obtendo valores médios de: (a) insolação - 2.131,35 horas de brilho solar ao ano, com máxima de $2.378,30$ e mínima de $1.508,10$ horas ao ano; (b) temperatura média anual - $20,80^{\circ} \mathrm{C}$, com máxima de $21,24^{\circ} \mathrm{C}$ e mínima de $19,44^{\circ} \mathrm{C}$; (c) umidade relativa média anual $-82,29 \%$, com máxima de $87,84 \%$ e mínima de $80,03 \%$; além de (d) precipitação e (e) evaporação. Quanto aos ventos, destacaram-se dois centros de massa de ar: o polar, proveniente do quadrante S-SE, com frequência de incidência de $42 \%$, provocando queda na temperatura local, principalmente nos meses de inverno, e o tropical atlântico proveniente do quadrante N-NE, com frequência de ocorrência de 56\%. Dados climáticos atualizados a cada 5 minutos e disponibilizados ao público podem ser obtidos na Estação Meteorológica 
da UFSC (LABHIDRO 2009).

Já os compostos húmicos $(\mathrm{CH})$ foram estudados no Manguezal do Itacorubi e em outros ambientes estuarinos da Ilha por Souza-Sierra et al. (1998) e Rauen et al. (2002). No primeiro estudo, definiuse que os $\mathrm{CH}$ estudados compõem um material geoquimicamente recente e pouco humificado, devido provavelmente à circulação e alta sedimentação no estuário. Ainda, pôde-se constatar que os sinais químicos e espectroscópicos emitidos pelos $\mathrm{CH}$ do Itacorubi são bem semelhantes aos do Manguezal de Ratones, um ambiente bem menos alterado por presença humana; ou seja, as diferenças entre $\mathrm{CH}$ de diferentes locais seriam devidas não somente à fonte do material de origem como também ao metabolismo das bactérias formadoras do húmus, além das características físico-químicas e geológicas do meio. No outro estudo, descobriu-se basicamente que com o aumento de acidez, força iônica e concentração de ácidos húmicos, a tensão superficial diminui.

Soriano-Sierra (1998a) e Soriano-Sierra et al. (1998a), por meio de análises multiparamétricas, analisaram a estrutura do mosaico ambiental no manguezal, evidenciandouma grandeheterogeneidade no habitat. Encontraram gradientes de salinidade de 4 a 40ppm, teores de matéria orgânica no sedimento com amplo espectro de variação espacial, porém compatíveis com os de outros manguezais e marismas encontrados na literatura. Soriano-Sierra (1998a) dividiu o manguezal, segundo essas análises, em biótopos inundados circadiariamente (substrato do manguezal, canais naturais e canais artificiais) e biótopos aquáticos permanentes (curso dos rios e confluência dos rios). Soriano-Sierra (1998b) e Haas (1990 apud Soriano-Sierra et al. 1998c) também estudaram fluxos de maré, hidrodinâmica e as interferências antropogênicas que as afetam, como funcionam os processos hidrodinâmicos internos, massas de água da rede fluvial e as implicações ecológicas desses processos. Os principais agentes da dinâmica estuarina local para os rios Itacorubi e Sertão são a precipitação e as alterações na temperatura ambiente (Santos 2007). Outros estudos que enriqueceram o conhecimento sobre a estrutura do Manguezal do Itacorubi foram feitos por SorianoSierra et al. (1983).

A contribuição de nutrientes antropogênicos para esse manguezal foi estudada por Soriano-Sierra \&
Sierra de Ledo (1998), que constataram que a taxa atual de entrada de nutrientes antropogênicos neste manguezal é maior que a capacidade funcional deste de suportá-la, o que tem causado uma acelerada eutrofização e consequente aumento da biomassa de fitoplâncton. Silva et al. (2005) afirmaram que os valores de nutrientes ao longo do rio Itacorubi indicam que está ocorrendo um processo de eutrofização.

Bainy et al. (2000) realizaram um estudo comparativo sobre a resposta bioquímica de mariscos (Perna perna Linnaeus, 1758) cultivados e transplantados para ambientes contaminados, entre eles o Manguezal do Itacorubi. Neste local, os mariscos apresentaram, após 150 dias, uma baixa atividade da glicose-6-fosfato-desidrogenase (G6PDH) e um aumento da atividade de glutationa-S-tranferase (GST) após 180 dias. Estas respostas estariam relacionadas às descargas de esgoto doméstico, que ainda sofreram influência, entre o $150^{\circ}$ e o $180^{\circ}$ dia, do aumento do índice que chuvas que acelerou o aporte destes efluentes para o estuário.

A análise qualitativa dos lipídios totais foi feita por Hansel (2000). Com o uso de Índices Preferenciais de Carbono (IPC) e a razão entre compostos de origem terrestre e aquática (RTA), avaliou a origem da matéria orgânica do Manguezal do Itacorubi, além de outros. Os IPCs aplicados para os ácidos carboxílicos variaram entre 5,2 e 8,0, tanto para o Itacorubi quanto para Ratones, indicando a presença de material de origem terrestre. Mater et al. (2004) obtiveram valores de IPCs de aproximadamente 3,5 para n-alcanos no sedimento, o que indica a predominância de aporte aquático autóctone. Já os valores de RTA para os ácidos mostraram que há matéria orgânica de origem aquática em todos locais estudados (Hansel 2000). Além disso, a contaminação por combustível fóssil não foi evidenciada nos manguezais de Itacorubi e Ratones. O autor sugeriu a utilização de um método de fracionamento para se detectar a contaminação por efluentes domésticos no Manguezal do Itacorubi, o que foi realizado por Mater et al. (2004), que constataram um nível elevado de coprostanol $(1,42 \mu \mathrm{g} / \mathrm{g})$, compatível com outros ambientes contaminados, e muito mais alto que ambientes preservados, como o Manguezal de Ratones (7,7ng/g).

O manguezal ao longo dos anos sofreu a ligação de diversas saídas de esgotos pluviais, sanitários e industriais, tanto públicos como privados. Até 2001, o 
número desses já estava em 85 (Sánchez Dalotto 2003). Em relação às características físicas do fluido desses esgotos, encontrava-se desde águas claras $(<1 \mathrm{UT})$ até águas com maior turbidez $(>5 \mathrm{UT})$, causada por sólidos em suspensão, azeites, combustíveis e sabões. Sobre o odor, as águas variavam de inodoras até com cheiro de azeite ou de material em estado de apodrecimento, característico do ambiente. Análises químicas revelaram que as águas dos esgotos encontravamse ligeiramente ácidas ou neutras, acidez essa que diminui a toxicidade de alguns componentes como a amônia. Além disso, apresentavam baixíssimos teores de oxigênio dissolvido, entre $1 \mathrm{mg} / 1$ a $2 \mathrm{mg} / 1$, menores do que o registrado por Panitz (1986) e Sierra de Ledo \& Soriano-Sierra (1998), o que é um tanto preocupante, ainda mais considerando que o nível mínimo aceitável para águas estuarinas é de $2 \mathrm{mg} / 1$ (Rabalais et al. 1991 apud Soriano-Sierra \& Sierra de Ledo 1998).

Pagliosa (2004) caracterizou através de variáveis físico-químicas e biológicas (fauna macrobentônica), os impactos da antropização sobre a macrofauna bêntica, as águas e os sedimentos, por meio da comparação entre áreas de rios não-urbanizados e urbanizados de Florianópolis. Os compostos nitrogenados apresentaram valores mais elevados para os rios urbanizados, bem como as concentrações de clorofila-a e feofitina-a. O silicato teve teores elevados para todas as áreas estudadas. As concentrações de silicato, nitrito, nitrato, amônia e fosfato registradas para os rios Itacorubi e outros urbanizados foram equivalentes e às vezes mais altas que as descritas para a Baía de Santos, Lagoa dos Patos e Baía da Guanabara, alguns dos sistemas estuarinos mais poluídos do Brasil, localizados em regiões de alta densidade populacional, intensa industrialização e zona portuária. Estes resultados evidenciaram que a descarga de esgotos nos corpos d'água pode causar valores muito elevados de nutrientes, independentemente da dimensão da malha urbana no entorno. Em outra parte do estudo, construíramse modelos preditivos para a comunidade bêntica baseados nas características da água e do sedimento, separando-se assim em dois grupos: 1) o das espécies sensíveis (indicadoras de boa qualidade ambiental): poliquetas Nephtys fluviatilis Monro, 1937 e Heteromastus similis Southern, 1921, e crustáceo Kalliapseudes schubarti Mane-garzon, 1969; 2) o das espécies tolerantes (indicadoras de má qualidade ambiental): poliqueta Laeonereis acuta Treadwell, 1923 e oligoqueta Tubificidae não identificado.

O manguezal apresenta quantidades elevadas de fósforo inorgânico na água e de polifosfato, seu derivado, no sedimento (Mater et al. 2004, Pagliosa 2004, Pagliosa et al. 2005). A presença de polifosfato, que não ocorre naturalmente em estuários, está associada à descarga de efluentes domésticos e industriais (Grasshoff et al. 1983 apud Pagliosa et al. 2005). A descarga abundante desses compostos no mar altera os fluxos naturais e a relação entre várias substâncias (Jickells 1998 apud Pagliosa et al. 2005). O despejo de esgoto interfere no balanço do influxo natural e aporte do fósforo, nitrogênio e carbono orgânico na interface água-sedimento nos dois rios do Itacorubi (Mater et al. 2004).

Hidrocarbonetos Policíclicos Aromáticos (HPA), compostos orgânicos provenientes da pirólise ou combustão incompleta da matéria orgânica, são potencialmente carcinogênicos. Oliveira (2006) analisou a biodegradação do pireno, um dos principais processos para sua remoção do meio ambiente. Apesar de toda a contaminação que tem ocorrido no Manguezal do Itacorubi, não foi encontrada contaminação por HPA na região analisada, dentro do limite de detecção do método. A porcentagem de recuperação média de pireno $(61 \pm 8,7 \%)$ ficou dentro da faixa permitida pela legislação atual.

\section{FATORES BIÓTICOS}

Relacionando os organismos estudados de acordo com sua complexidade, inicialmente temos o estudo com bactérias feito por Souza \& Napoleão (2002), que coletaram duas amostras para exames de coliformes totais e fecais, uma diretamente da tubulação pluvial da UDESC e outra do canal que passa em frente à universidade, sendo que ambos desembocam no rio Itacorubi. Os resultados foram críticos, pois a concentração de coliformes totais $(1.600 .000 \mathrm{nmp} / 100 \mathrm{ml})$ chegava a estar 320 vezes acima da permitida pela legislação vigente na época; atualmente estaria 400 vezes acima da concentração permitida pelo Conselho Nacional do Meio Ambiente (CONAMA 2005). Além disso, a quantidade de coliformes fecais $(300.000 \mathrm{nmp} / 100 \mathrm{ml})$ se encontrava 300 vezes acima do máximo permitido pela legislação 
anterior e atual. Em 2006, Vieira realizou uma nova análise bacteriológica nos rios, afluentes e canais que convergem para o manguezal. O resultado foi de que todas as análises, exceto para o canal de saída do CTReS, registraram $16.000 \mathrm{nmp} / 100 \mathrm{ml}, 16$ vezes acima do permitido para coliformes fecais e 4 vezes acima para coliformes totais. A redução se deve à entrada em funcionamento da rede coletora de esgoto da Bacia Hidrográfica do Itacorubi em 2003 (Vieira 2007). Apesar disso, o teor de coliformes continua acima do aceitável, possivelmente devido ao fato de que a ligação à rede não é compulsória; assim, boa parcela da população continua no sistema antigo de fossa séptica e de lançamento direto na rede de drenagem pluvial.

Laut et al. (2007) analisaram a relação entre a distribuição das populações de foraminíferos e a atividade respiratória bacteriana no sedimento e sua significância ecológica para diagnóstico no estuário do rio Itacorubi. Vinte e oito espécies de foraminíferos foram identificadas, com dominância de Ammonia beccarii Linnaeus, 1758 nas porções mais externas do estuário e Arenoparrella mexicana Topsent, 1904 nas mais internas. A frequência relativa de A. mexicana foi relacionada positivamente com enriquecimento orgânico, hipoxia e presença de bactérias redutoras de sulfato. Ocorreu o oposto com as espécies calcárias, sobretudo A. beccarii. Os resultados mostraram um gradiente de recuperação ambiental em direção ao mar e um estresse ambiental maior nas áreas adjacentes ao antigo aterro sanitário.

Estudandoas algas bentônicas sobrepneumatóforos de Laguncularia racemosa e A. schaueriana, Hadlich (1983) encontrou 15 espécies de algas, sendo seis Chlorophyta (Hadlich 1984) e nove Rhodophyta (Hadlich \& Bouzon 1985).

A respeito da comunidade fitoplanctônica, Vieira (1987) identificou que nas regiões mais estuarinas havia predomínio de algas crisófitas, seguidas por cianófitas e clorófitas. Em ambos os rios que desembocam no manguezal, as bactérias e protozoários prevaleciam sobre as algas. No rio Sertão, havia uma maior contribuição percentual de Euglenophyta, com os gêneros Euglena e Phacus, característicos de águas ricas em matéria orgânica e poluídas. O grupo das clorófitas era mais abundante nesse local com formas filamentosas e solitárias, sendo os gêneros principais Closterium e Scenedesmus, que também são característicos de águas poluídas. No rio Itacorubi, o principal grupo algal era o das Chrisophyta, seguido por Cyanophyta. Através do método do oxigênio dissolvido, Bahia (1987), de maio a outubro de 1986, estudou a produção primária do fitoplâncton no Manguezal do Itacorubi. Concluiu que o ecossistema é eutrófico, tanto pelos valores médios de produção primária bruta $\left(288,77 \mathrm{mgC} / \mathrm{m}^{3} / \mathrm{h}\right)$, quanto pelo Índice de Margalef $(1,9)$; e quanto mais próxima do estuário, mais produtiva a área, devido à ação de fatores como as marés, esgotos e comunidade planctônica (Vieira 1987). Ainda, apresentou sugestões para estudos futuros, por meio da modificação dos métodos empregados, estimativa diurna da produção primária e parâmetros ambientais relacionados, avaliação mais precisa do efeito das marés, avaliação da produção primária na coluna vertical d'água, avaliação da capacidade e eficiência fotossintética do fitoplâncton, e análise de regressão linear múltipla entre os fatores ambientais e produção primária.

Coletando basidiomas, Trierveiler-Pereira et al. (2007) e Trierveiler-Pereira et al. (2009) identificaram as espécies de fungos xilófilos dos manguezais de Florianópolis. Embora Itacorubi seja o mais degradado da Ilha, foi registrado o maior número de espécies (25). Isto contrariou Penttilä et al. (2006 apud Trierveiler-Pereira et al. 2007), pois segundo eles, a fragmentação e perda de habitats influenciam a diversidade fúngica negativamente. Além disso, Trierveiler-Pereira et al. (2008a) fizeram o primeiro registro de mixomicetos em A. schaueriana, coletando no Manguezal do Itacorubi três espécies nunca antes vistas em manguezais do Brasil. Também foram feitas buscas no Manguezal do Saco Grande, onde se obteve uma espécie, e nos outros manguezais da Ilha, onde nenhuma espécie de mixomiceto foi encontrada. Em outro estudo, Trierveiler-Pereira et al. (2008b) descobriram que L. racemosa (Linnaeus) Gaertn, 1807 também é hospedeira do fungo anamórfico Cytospora rhizophorae Kohlm \& E. Kohlm, 1971, que previamente havia sido encontrado parasitando outras espécies de mangue. Esse registro em L. racemosa ocorreu no Manguezal de Saco Grande, enquanto que no Itacorubi e Rio Tavares, C. rhizophorae foi encontrado em Rhizophora mangle Linnaeus, 1753. Ainda, Baltazar et al. (2009) descobriram uma nova espécie, Fuscoporia bifurcata Baltazar et al. 2009, nos manguezais de Florianópolis, sendo que no do 
Itacorubi, o espécime foi encontrado em um tronco em decomposição de A. schaueriana. Todas essas descobertas mostram o potencial de novos estudos sobre fungos a serem realizados nessa área.

Soriano-Sierra et al. (1998b) fizeram um levantamento da comunidade de plantas. A baixíssima diversidade é influenciada principalmente pela salinidade e falta de oxigênio (CETESB 1983 apud De La Corte 1995). As três espécies típicas de mangue na Ilha de Santa Catarina são $A$. schaueriana, $L$. racemosa e $R$. mangle (Souza-Sobrinho et al. 1969), além das gramíneas Spartina densiflora Brongn, 1829 e S. alterniflora, também chamadas de capim-praturá, que compõem as marismas. Essas foram amplamente estudadas por Panitz (1986, 1987a, 1987b, 1989, 1992), por Panitz \& Masutti (2000a, 2000c) e por Masutti \& Panitz (2000). Ainda segundo Soriano-Sierra et al. (1998b), nas áreas de transição manguezal-restinga foram encontradas Hibiscus tiliaceus var. pernambucensis (Arruda) Johnston, 1949, Rapanea parvifolia (DC.) Mez, 1902, Dalbergia ecastaphyllum (Linnaeus) Taubert, 1894, Annona glabra Linnaeus, 1753 e Acrostichum aureum Linnaeus, 1753. O autor ainda determinou a densidade e estrutura das populações das espécies típicas. $A$. schaueriana, L. racemosa e $R$. mangle apresentaram 800, 200 e 100indivíduos/ha respectivamente. Dentre as plântulas, a densidade média fica em 39, 138 e 868indivíduos/ha.

Panitz (1986, 1992) determinou a variação sazonal da biomassa e da composição química de S. alterniflora, sua densidade e altura, estimou a serapilheira total e frações do mangue, o valor de meia-vida, determinou a composição química foliar das três espécies arbóreas típicas do manguezal, determinou e comparou as taxas de decomposição a diferentes condições e relacionou os processos de produção e decomposição de serapilheira com condições ambientais. Uma de suas conclusões foi a de que o bosque de mangue do rio Itacorubi mostrou uma produção de serapilheira relativamente reduzida $\left(2,37 \mathrm{~g} / \mathrm{m}^{2} / \mathrm{dia}\right)$, provavelmente devido ao seu baixo desenvolvimento estrutural. Por fim, sugeriu uma série de estudos, tais como determinar o grau de herbivoria das plantas do mangue, entre outros.

$\mathrm{O}$ uso de parâmetros foliares para avaliar o efeito dos tensores sobre manguezais da Grande Florianópolis foi feito por Panitz (1993) no Itacorubi e por Felipe (1998) em Ratones e em Palhoça. O melhor parâmetro testado foi o da área foliar (Panitz 1993), e os melhores métodos de determinação dessa área foram o planimétrico e o da área milimetrada (Felipe 1998). Segundo Felipe (1998), a canalização e o aterramento reduziram a área foliar e afilaram as folhas de $L$. racemosa, enquanto o esgoto arredondou as folhas de $A$. schaueriana. Por outro lado, o esgoto causou o desenvolvimento de folhas maiores de A. schaueriana e R. mangle (Panitz 1993), sendo possivelmente uma compensação das plantas à diminuição da superfície fotossintética perdida pela acentuada queda e pelas alterações fisiológicas ocorridas nas folhas (Ponte et al. 1987 apud Felipe 1998, Rodrigues et al. 1989 apud Felipe 1998). Já Cunha (2003), examinou a influência dos líquidos percolados do aterro desativado no desenvolvimento de A. schaueriana no Itacorubi, constatando alterações nas variáveis biométricas e morfoanatômicas. Apesar de haver um incremento no padrão de crescimento nas plantas sujeitas a esses líquidos percolados (provavelmente devido aos nutrientes presentes nesses líquidos), essas mesmas plantas sofreram diversas alterações negativas, tais como redução no número médio de estômatos $\mathrm{e}$ glândulas de sal. Clorose, deformações, necrose de parte das folhas e maior suscetibilidade a organismos agressores foram registradas em $42 \%$ das folhas das plantas tratadas com o efluente, contra $7 \%$ das tratadas com água. O autor sugere estudos complementares e correções, tais como a investigação das concentrações de metais pesados e a verificação da hipótese de que os aumentos na área foliar e no tamanho das células epidérmicas poderiam influir nos resultados obtidos.

Ainda, Oliveira \& Panitz (2003), estudaram a cobertura do manguezal pelas espécies arbóreas A. schaueriana, L. racemosa e $R$. mangle. No Manguezal do Itacorubi encontraram 45,82\% de cobertura vegetal, enquanto que no Manguezal do Rio Tavares esse índice foi de $46 \%$, no Manguezal do Saco Grande $31 \%$ e no Manguezal do Rio Ratones apenas $15,3 \%$, mostrando que ainda há uma razoável cobertura no Itacorubi, apesar do grau crescente de urbanização. Já a distribuição das espécies segue o padrão de zoneamento de manguezais na região sul do Brasil: L. racemosa em áreas afastadas e pouco atingidas pelas marés, A. schaueriana em áreas permanentemente alagadas pelas marés, $R$. mangle em áreas frequentemente inundadas pelas marés 
(Sánchez Dalotto 2003). Na Ilha de Santa Catarina, as condições térmicas para o bosque de mangue constituem um fator de estresse natural, enquanto que as amplitudes das marés locais também não favorecem sua expansão. Porém, o bom desenvolvimento registrado na vegetação parece dever-se à qualidade das fontes de energia auxiliar disponíveis no local (Sierra de Ledo \& Soriano-Sierra 1998b).

Huber (2004) efetuou um estudo comparativo de restauração de áreas degradadas de manguezal comparando o Manguezal do Itacorubi, com o de Saco Grande e o da Praia da Bina, localizado em Biguaçu. Um dos trabalhos analisados foi o de Cunha (2000), que realizou no Itacorubi o plantio de 225 mudas de Avicennia, em $360 \mathrm{~m}^{2}$ de clareira, em três áreas com diferentes graus de inundação. Obteve uma taxa de sobrevivência após 18 meses de 93,33\% e após 45 meses de $67,56 \%$, com média de crescimento de $0,61 \mathrm{~m} /$ ano na altura e incremento de $0,90 \mathrm{~cm} /$ ano no diâmetro da base. Na comparação com as outras áreas, Huber (2004) mostrou que a taxa de sobrevivência foi maior em relação à da Praia da Bina $(23,10 \%)$, uma região altamente degradada, e menor do que no Saco Grande (90,51\%), que é uma região menos impactada do que as outras duas. Concluiu que a presença do lixo e do homem, seja ele pescador ou catador, influenciou negativamente o desenvolvimento das plantas. A herbivoria pareceu não ter muita interferência, mas a presença de galhas, fungos e cochonilhas no Manguezal do Itacorubi é grande, provavelmente por maior suscetibilidade das plantas aos efeitos da poluição oriunda do chorume do lixão desativado. Já uma caracterização da fenologia do manguezal foi feita por Panitz (1999a). Além de mostrar que as espécies de mangue têm várias florações durante o ano, principalmente no verão, indicou que os frutos são bastante atacados por insetos e fungos. Ainda, o valor nutritivo do folhedo do manguezal foi descrito por Panitz (1990) e um mapeamento temático e classificação da vegetação por sensoriamento remoto foi produzido por Panitz (1999b).

Pagliosa (2004), cujo estudo caracterizou as espécies da macrofauna bêntica, encontrou, uma espécie de Mollusca (Heleobia australis D’Orbigny, 1835), cinco de Polychaeta (Heteromastus similis Southern, 1921, Laeonereis acuta Treadwell, 1923, Glycinde multidens Müller, 1858, Capitella sp. Blainville, 1828, Scoloplos sp. Blainville, 1828), uma de Oligochaeta (Tubificidae), duas de Crustacea (Anomura e Kalliapseudes schubarti Mañé-Garzon, 1949), uma de Insecta (Nematocera) e uma de Nematoda para o Manguezal do Itacorubi. Como seu objetivo não era o de realizar um levantamento taxonômico e seu estudo não levou em consideração o componente temporal, muitas outras espécies ainda podem ser descobertas para a região.

Dentre os moluscos característicos da região, destacam-se o mexilhão (M. guyanensis), o berbigão (Anomalocardia brasiliana Gmelin, 1791), o cafezinho (Melampus coffeus Linnaeus, 1758), a ostra (Crassostraea rhizophorae Guilding, 1828), os caramujos (Littorina spp.), além de outros (Panitz 1997a, Lacerda 1999 apud Gonzalez 2004). A filtração de bactérias pela ostra (Ceruti \& Barbosa 1989) e a ocorrência e distribuição do mexilhão (Ribeiro, 1999) também foram estudadas nesse manguezal. Essas espécies são utilizadas para fins de subsistência das populações ribeirinhas desse ambiente. O mexilhão (M. guyanensis) é a única espécie do gênero no Itacorubi, embora outra espécie (Mytella falcata) ocorra em outros manguezais de Florianópolis (Ribeiro 1999). Através de um estudo no Manguezal do Itacorubi, descobriu-se que o mexilhão possui hábito gregário, com densidade de até 30 indivíduos/ $\mathrm{m}^{2}$ no rio Sertão, próximo a confluência dos rios, e é virtualmente ausente no setor desse rio próximo ao Shopping Center Iguatemi. Além disso, apresenta maior frequência nas classes de $40-45 \mathrm{~cm}$ e $50 \mathrm{c}-55 \mathrm{~cm}$ de comprimento. Ainda, possui preferência por se instalar junto aos pneumatóforos de A. schaueriana. Comprovou-se, através de pesquisas realizadas no Manguezal do Itacorubi, que o ecossistema desempenha a função de criadouro natural dessas espécies essenciais para a região, assim, devendo ser conservado (Panitz 1997a). Faltam estudos mais atuais para definir como é sua situação hoje no manguezal.

Spivak (1997) fez uma análise dos caranguejos estuarinos do Atlântico sul, entre as latitudes $25^{\circ} \mathrm{S}$ e $41^{\circ} \mathrm{S}$. Observou uma brusca queda no número de espécies conforme se aumentava a latitude, concluindo que os principais fatores relacionados a isso são a diminuição na temperatura e o desaparecimento dos manguezais e a variedade de microhabitats gerados por eles. Estudando crustáceos no Manguezal do Itacorubi, Branco (1991, 1998b) encontrou quatro espécies de camarão de água salgada, uma espécie de camarão de 
água doce, 12 espécies de caranguejo e cinco espécies de siri. Seus trabalhos ainda abordaram observações etológicas, distribuição espacial e abundância relativa no ciclo anual, concluindo que apesar de alterado, este manguezal ainda é adequado ao desenvolvimento dos crustáceos decápodos. Publicaram também estudos com Ucides cordatus Linnaeus, 1753 (Branco 1998a), Aratus pisonii Edwards, 1837 (Ávila \& Branco 1998) e Callinectes danae Smith, 1869 (Branco \& Thives 1998), essa última a espécie dominante.

A fauna de drosofilídeos foi caracterizada por Schmitz et al. (2007), através de um estudo sazonal entre 2002 e 2005. Cinquenta e uma espécies de cinco gêneros de Drosophilidae foram encontradas no Manguezal do Itacorubi, 11 espécies a mais que o encontrado em um estudo anterior (Schmitz 2004), enquanto que em outros manguezais menos urbanizados da Ilha esse número ficou em 48 (Rio Tavares) e 45 (Rio Ratones). A diferença entre as abundâncias dos locais, no entanto, foi grande, o que poderia estar indicando respostas diferentes às pressões ambientais em ação nos manguezais. Outros insetos não tiveram nenhum estudo específico, nem mesmo os de importância médica como os mosquitos, por exemplo.

Em se tratando de vertebrados, a composição da ictiofauna levantada por Clezar et al. (1998a) indicou a presença de 49 espécies de 23 famílias, das quais se destacaram Engraulidae e Mugilidae, com $68,2 \%$ e $15,5 \%$, respectivamente, do total de exemplares coletados. Clezar $(1987,1998)$ e Clezar et al. (1998b, 1998c) estudaram a ocorrência, abundância, distribuição, crescimento, relação peso total/ comprimento e outros aspectos ecológicos da manjuba (Cetengraulis edentulus Cuvier, 1829), no manguezal de Itacorubi. A abundância relativa e distribuição de corvina (Micropogonias furnieri Desmarest, 1822) e pescada-branca (Cynoscion leiarchus Cuvier, 1830) foram estudadas por Hostim-Silva (1998). Já Hass et al. (1989) e Ribeiro et al. (1988, 1989, 1998) estudaram a ocorrência, abundância e distribuição de mugilídeos (tainhas), além de outros aspectos de sua ecologia.

Quanto à herpeto fauna, não há nenhum levantamento de espécies publicado, nem mesmo parcial, paraa Ilha(CECCA1997)oupara o Manguezal. Apesar disso, a presença de pelo menos uma família de jacarés-do-papo-amarelo (Caiman latirostris Daudin, 1802) é visível no Manguezal do Itacorubi (Menegotto
2008). Os indivíduos dessa espécie atraem a atenção das pessoas, ao permanecerem durante parte do dia no rio Sertão, próximos ao Shopping Center Iguatemi. É imprescindível que tanto essa(s) família(s) de jacarés, quanto as outras espécies de répteis e anfíbios sejam amostrados e estudados, devido a sua importância principalmente local.

A mastofauna do Manguezal do Itacorubi foi caracterizada em uma pesquisa de Graipel et al. (2001), com exceção dos mamíferos voadores (Chiroptera), que ainda não foram estudados no local, mas que devem ocorrer, assim como em outros manguezais do sul do Brasil (Bordignon 2006, ÁvilaFlores et al. 2002). Como a maioria dos mamíferos presentes em manguezais possui hábitos noturnos, são dificilmente observados. Graipel et al. (2001) relataram as seguintes espécies: Didelphis aurita Wied-Neuwied, 1826 (gambá-de-orelha-preta), Lutreolina crassicaudata Desmarest, 1804 (cuícade-cauda-grossa), Lontra longicaudis Olfers, 1818 (lontra), Myocastor coypus Molina, 1782 (ratão-dobanhado).

O homem como espécie que utiliza o mangue para sua subsistência também deve ser incluído como um fator biótico e estudado através de pesquisas etnoecológicas. Nenhum estudo mais aprofundado e atual foi feito a respeito, apenas sabe-se que na década passada o manguezal era utilizado para a pesca de subsistência por uma pequena quantidade de pessoas e para a pesca amadora por outras. (Soriano-Sierra et al. 1998c).

Em relação à avifauna, o primeiro levantamento que estudou espécies desse manguezal foi realizado por Sick et al. (1979), seguido por Sick et al. (1981), embora não houvesse um foco apenas nesse ambiente. Em 1985, foi acrescentada à lista de espécies desse manguezal, a saracura-matraca (Rallus longirostris Boddaert, 1783), considerada rara, residente e nidificante (Bege 1998 apud Naka \& Rodrigues 2000). Segundo Panitz (1997a), pássaros migratórios podem voar longas distâncias para encontrar alimento e locais para fazer ninhos nos manguezais. Entre as aves que vêm procurar alimento no Manguezal do Itacorubi, predominam as seguintes espécies: Haematopus palliatus Temminck, 1820 (caçador de ostras), Charadrius collaris Vieillot, 1818 (batuíra-decoleira), Casmerodius albus Linnaeus, 1758 (garçabranca-grande), Egretta thula Molina, 1782 (garçabranca-pequena), Syrigma sibilatrix Temminck, 1824 
(maria-faceira), Phalacrocorax olivaceus Humboldt, 1905 (biguá), Chloroceryle amazona Latham, 1790 (martim-pescador-verde), Larus dominicanus Lichtenstein, 1823 (gaivotão), Sterna hirundinacea Lesson, 1831 (trinta-réis-de-bico-vermelho). Além dessas, também ocorrem ocasionalmente outras, tais como, marrecas, andorinhas, sabiás, picapaus e gaviões. Já entre as aves que nidificam no manguezal, estão presentes espécies das famílias Ardeidae (garças e socós), Rallidae (saracuras), Threskiornithidae (colhereiros), Tyrannidae (bem-tevis) e Troglodytidae (corruíras). Em 2007, Amorim \& Piacentini estenderam o limite sul de distribuição da figuinha-do-mangue (Conirostrum bicolor Vieillot, 1807) para esse manguezal. A mesma espécie também foi observada no Manguezal de Ratones. O registro de outras espécies pode ser facilmente estendido ao Manguezal do Itacorubi assim que estudos mais detalhados sejam realizados.

\section{CONCLUSÃO}

Apesar da grande quantidade de estudos ecológicos nesses últimos 40 anos, muito ainda precisa ser feito para garantir a conservação desse ecossistema fundamental à manutenção da vida. Pesquisas e ações indispensáveis à melhor compreensão do Manguezal do Itacorubi foram sugeridas em cada tópico. Aqui se apresenta uma lista sucinta (Tabela II) dos temas que foram realizados há mais de uma década e, portanto, estão desatualizados, além dos estudos feitos que são insuficientes e os que nunca foram feitos. Somente com estes é que os planos de conservação para o Manguezal do Itacorubi podem ser efetivados de maneira correta.

Tabela II. Pesquisas que devem ser realizadas no Manguezal do Itacorubi, por estarem desatualizadas, serem insuficientes ou inexistentes.

Table II. Ecological topics in need of further investigation at the mangrove swamp of Itacorubi. Current data in these fields is either outdated, scarce,

$$
\text { or lacking. }
$$

\begin{tabular}{cc}
\hline Assunto & Motivo \\
\hline Avifauna & Desatualização \\
Parâmetros físico-químicos & Desatualização \\
Entomofauna & Insuficiência \\
Etnoecologia & Desatualização \\
Fitobentos & Desatualizção \\
Herpetofauna & Inexistência \\
Ictiofauna & Desatualização \\
Malacofauna & Desatualização \\
Quiropterofauna & Inexistência \\
Plâncton & Desatualização \\
Zoobentos & Insuficiência \\
\hline
\end{tabular}

Sierra de Ledo \& Soriano-Sierra (1998a, 1998c) fizeram uma caracterização ambiental do manguezal, discutiram os efeitos dos impactos humanos e as ações de manejo, resumindo o que foi dito anteriormente e exacerbando a importância de se conservar esse ambiente. Camargo (2001), por sua vez, elaborou um abrangente estudo que culminou em propostas para o zoneamento ambiental dos Manguezais do rio Ratones e do rio Tavares, através do uso do Sistema de Informação Geográfica (SIG). Propostas essas que poderiam ser bem aproveitadas no caso do Manguezal do Itacorubi.

As recentes transformações causadas pelo Shopping Center Iguatemi, cuja implantação foi marcada por denúncias de compra de licença ambiental e por muitas irregularidades durante todo o processo de licenciamento e construção, precisam ainda ser mensuradas em termos do impacto causado na área a curto, médio e longo prazo, bem como a construção de novas vias de acesso, a canalização de parte do rio Sertão e o aumento do aporte de efluentes causado pelo empreendimento.

Futuros estudos deverão preencher a lacuna no conhecimento referente à ecologia do manguezal. $\mathrm{O}$ monitoramento temporal periódico de dados físicos, químicos e biológicos, é de suma importância para avaliação do ambiente, e fundamental para futuras propostas de conservação, manejo e educação ambiental acerca do Manguezal do Itacorubi e da bacia hidrográfica que o inclui.

AGRADECIMENTOS: Agradeço ao colega de curso Philipy Alexandre Pereira Weber pela ajuda na elaboração do texto durante a parte inicial do estudo, à bibliotecária e minha mãe Vera Ingrid Hobold Sovernigo pelo apoio logístico e afetivo, aos revisores que ajudaram a aprimorar o trabalho e aos professores Mauricio Mello Petrúcio e Eduardo Juan Soriano-Sierra que incentivaram o desenvolvimento do mesmo, tornando assim possível sua publicação.

\section{REFERÊNCIAS}

ALIANÇA NATIVA. 2009. Ações e Projetos da Aliança Nativa. http://www.aliancanativa.org.br/projetos.php. (Acesso em 08/05/2009).

AMORIM, J.F. \& PIACENTINI, V.Q. 2007. Novas áreas de ocorrência de três Passeriformes no sul do Brasil. Lundiana, 8(1): 69-73. 
ÁVILA, M.G. \& BRANCO, J.O. 1998. Estrutura populacional de Aratus pisonii (H. Milne Edwards 1837) (Decapoda, Grapsidae), no Manguezal de Itacorubi, SC, Brasil. Pp. 179-190. In: E.J. Soriano-Sierra \& B. Sierra de Ledo (eds.). Ecologia e Gerenciamento do Manguezal de Itacorubí. NEMAR/CCB/ UFSC, SDM/FEPEMA, Florianópolis. 440p.

ÁVILA-FLORES, R.; FLORES-MARTÍNEZ, J.J. \& ORTEGA, J. 2002. Nyctinomops laticaudatus. Mammalian Species, 697(1): $1-6$.

AYALA, L. 2004. A relação do espaço na evolução morfodinâmica do Manguezal do Itacorubi, Florianópolis, SC. Tese de Doutorado. Programa de Pós Graduação de Geociências da Universidade Federal do Rio Grande do Sul, Porto Alegre, Brasil. 273p.

BAHIA, E.W. 1987. Estudo comparativo da produção primária do fitoplâncton no Manguezal do Itacorubi - Ilha de Santa Catarina, Florianópolis/SC. Trabalho de Conclusão de Curso. Curso de Graduação em Ciências Biológicas da Universidade Federal de Santa Catarina, Florianópolis, Brasil. 100p.

BAINY, A.C.D.; ALMEIDA, E.A.; MÜLLER, I.C.; VENTURA, E.C. \& MEDEIROS, I.D. 2000. Biochemical responses in farmed mussel Perna perna transplanted to contaminated sites on Santa Catarina Island, SC, Brazil. Marine Environmental Research, 50: 411-416.

BALTAZAR, J.M.; PEREIRA, L.T; LEITE, C.L. \& RYVARDEN, L. 2009. Santa Catarina Island mangroves 3 - A new species of Fuscoporia. Mycologia, 8: 80-82.

BORDIGNON, M.O. 2006. Padrão de atividade e comportamento de forrageamento do morcego-pescador Noctilio leporinus (Linnaeus) (Chiroptera, Noctilionidae) na Baía de Guaratuba, Paraná, Brasil. Revista Brasileira de Zoologia, 23(1): 50-57.

BRANCO, J.O. 1991. Aspectos ecológicos dos Brachyura (Crustacea: Decapoda) no Manguezal do Itacorubi, SC, Brasil. Revista Brasileira de Zoologia, 7(1-2): 165-179.

BRANCO, J.O. 1998a. Aspectos bioecológicos do caranguejo Ucides cordatus (Linnaeus, 1763) (Crustácea Decapoda) do manguezal de Itacorubí na Ilha de Santa Catarina, Brasil. Pp. 163178. In: E.J. Soriano-Sierra \& B. Sierra de Ledo (eds.). Ecologia e Gerenciamento do Manguezal de Itacorubí. NEMAR/CCB/ UFSC, SDM/FEPEMA, Florianópolis. 440p.

BRANCO, J.O. 1998b. Crustáceos decápodos do manguezal de Itacorubí na Ilha de Santa Catarina, Brasil. Pp. 139-144. In: E.J. Soriano-Sierra \& B. Sierra de Ledo (eds.). Ecologia e Gerenciamento do Manguezal de Itacorubí. NEMAR/CCB/ UFSC, SDM/FEPEMA, Florianópolis. 440p.
BRANCO, J.O. \& THIVES, A. 1998. Relação peso/largura, fator de condição e tamanho de primeira maturação de Callinectes danae Smith 1869 (Crustacea, Portunidae) no manguezal de Itacorubí na Ilha de Santa Catarina, Brasil. Pp. 191-204. In: E.J. SorianoSierra \& B. Sierra de Ledo (eds.). Ecologia e Gerenciamento do Manguezal de Itacorubí. NEMAR/CCB/UFSC, SDM/FEPEMA, Florianópolis. 440p.

CAMARGO, L.P. 2001. Proposta de zoneamento ambiental para os manguezais do Rio Ratones, Saco Grande e Rio Tavares, Ilha de Santa Catarina através do geoprocessamento como subsídio ao gerenciamento costeiro (GERCO) de Santa Catarina. Dissertação de Mestrado. Programa de Pós Graduação de Engenharia Ambiental da Universidade Federal de Santa Catarina, Florianópolis, Brasil. 220p.

CECCA (Centro de Estudos Cultura e Cidadania). 1997. Uma cidade numa ilha: relatório sobre os problemas sócioambientais da Ilha de Santa Catarina (Segunda edição). Insular, Florianópolis. 247p.

CERUTI, R.L. \& BARBOSA, T.C. 1989. Poluição bacteriana de águas da Baía norte e mangue do Itacorubi - Ilha de Santa Catarina e sua retenção pelos bivalves (Crassostrea rhizophorae Guilding 1928). Caderno Temático de Pesquisas da UFSC, 1(1): 31-32.

CETESB (Companhia Estadual de Tecnologia de Saneamento Ambiental de São Paulo). 1979. Resíduos sólidos no mangue do Itacorubi, Florianópolis - Impacto Ambiental. Proposta CETESB 702425, Brasil. 86p.

CGA (Coordenadoria de Gestão Ambiental). 2006. A CGA. http:// www.cga.ufsc.br/cga.htm. (Acesso em 16/06/2009).

CLEZAR, L. 1987. Ocorrência e aspectos ecológicos de integrantes da família Engraulidae (Osteichthyes, Clupeiformes) no Manguezal de Itacorubi, Florianópolis/SC, Brasil. Trabalho de Conclusão de Curso. Curso de Graduação em Ciências Biológicas da Universidade Federal de Santa Catarina, Florianópolis, Brasil. $77 \mathrm{p}$.

CLEZAR, L. 1998. Crescimento de Cetengraulis edentulus (Cuvier 1829) (Clupeiformes, Engraulidae) no Manguezal de Itacorubí, SC, Brasil. Pp. 229-238. In: E.J. Soriano-Sierra \& B. Sierra de Ledo (eds.). Ecologia e Gerenciamento do Manguezal de Itacorubí. NEMAR/CCB/UFSC, SDM/FEPEMA, Florianópolis. 440p.

CLEZAR, L.; HOSTIM-SILVA, M. \& RIBEIRO, G.C. 1998a. Comunidade de peixes do Manguezal de Itacorubí, Ilha de Santa Catarina, SC, Brasil. Pp. 205-216. In: E.J. Soriano-Sierra \& B. 
Sierra de Ledo (eds.). Ecologia e Gerenciamento do Manguezal de Itacorubí. NEMAR/CCB/UFSC, SDM/FEPEMA, Florianópolis. 440 .

CLEZAR, L.; HOSTIM-SILVA, M. \& RIBEIRO, G.C. 1998b. Relação peso total/comprimento e fator de condição da manjuba Cetengraulis edentulus(Cuvier 1829)(Clupeiformes, Engraulidae) no Manguezal de Itacorubí, Ilha de Santa Catarina, SC, Brasil. Pp. 239-246. In: E.J. Soriano-Sierra \& B. Sierra de Ledo (eds.). Ecologia e Gerenciamento do Manguezal de Itacorubí. NEMAR/ CCB/UFSC, SDM/FEPEMA, Florianópolis. 440p.

CLEZAR, L.; HOSTIM-SILVA, M.; RIBEIRO, G.C. \& SIERRA DE LEDO, B. 1998c. Abundância e distribuição de Cetengraulis edentulus (Cuvier 1829) (Clupeiformes, Engraulidae) no Manguezal de Itacorubí, SC, Brasil. Pp. 217-228. In: E.J. SorianoSierra \& B. Sierra de Ledo (eds.). Ecologia e Gerenciamento do Manguezal de Itacorubí. NEMAR/CCB/UFSC, SDM/FEPEMA, Florianópolis. 440p.

COLLARES, D.; FREITAS, F.H.M.; SCHWEIG, L.; FIGUEIREDO, L.C.; GRÜDTNER, M.; MARQUETTI, M.; FIGUEIREDO, T.; MARTINS, T.P.; NASPOLINI, V. \& TISCHER, W. 2004. A Bacia do Itacorubi. http://www.arq.ufsc. br/urbanismoV/2004-1/final.pdf. (Acesso em 05/05/2009).

COMCAP (Companhia de Melhoramento da Capital). 2003. CETRES. http://www.comcap.org.br/index. php?link=conhecendo. (Acesso em 27/04/2008).

CONAMA (Conselho Nacional do Meio Ambiente). 2005. Resolução $n^{\circ}$ 357, 17 de março de 2005. Ministério do Meio Ambiente, Brasil.

CUNHA, R.P. 2000. Avaliação do plantio experimental de Avicennia schaueriana Stapf \& Leechman em uma área degradada do manguezal do Itacorubi; Florianópolis-SC. Trabalho de Conclusão de Curso. Curso de Graduação em Ciências Biológicas da Universidade Federal de Santa Catarina, Florianópolis, Brasil. $77 \mathrm{p}$.

CUNHA, R.P. 2003. Influência dos líquidos percolados do aterro de lixo da cidade de Florianópolis-SC, Brasil, no desenvolvimento de Avicennia schaueriana Stapf \& Leechman.ex Moldenke. Dissertação de Mestrado. Programa de Pós Graduação de Biologia Vegetal da Universidade Federal de Santa Catarina, Florianópolis, Brasil. 146p.

DE LA CORTE, F.S. 1995. Contribuição para o conhecimento do balanço de importação/exportação de matéria entre o Manguezal do rio Itacorubi e a Baia Norte proximal (Ilha de Santa Catarina, Brasil). Trabalho de Conclusão de Curso. Curso de Graduação em Ciências Biológicas da Universidade Federal de Santa Catarina, Florianópolis, Brasil. 73p.
DUTRA, S.J. 1994. Aspectos morfométricos e da sua utilização humana da Bacia do Córrego Grande, Ilha de Santa Catarina, SC, Brasil. Pp: 244-244. In: Anais do II Seminário de Pesquisa da UFSC. Florianópolis, SC. 1v.

DUTRA, S.J. 1998. A Bacia hidrográfica do Córrego Grande, Ilha de Santa Catarina, Brasil. Pp. 31-46. In: E.J. Soriano-Sierra \& B. Sierra de Ledo (eds.). Ecologia e Gerenciamento do Manguezal de Itacorubí. NEMAR/CCB/UFSC, SDM/FEPEMA, Florianópolis. 440p.

FELIPE, A. 1998. Área foliar como um indicador ecológico da qualidade ambiental dos manguezais da Grande Florianópolis, SC. Trabalho de Conclusão de Curso. Curso de Graduação em Ciências Biológicas da Universidade Federal de Santa Catarina, Florianópolis, Brasil. 74p.

GONZALEZ, B.C. 2004. Subsidios para uma proposta de um programa de educação ambiental para o Parque Manguezal do Itacorubi, Florianópolis-SC, Brasil. Trabalho de Conclusão de Curso. Curso de Graduação em Ciências Biológicas da Universidade Federal de Santa Catarina, Florianópolis, Brasil. $76 \mathrm{p}$.

GRAIPEL, M.E.; CHEREM, J.J. \& XIMENEZ A. 2001. Mamíferos terrestres não voadores da Ilha de Santa Catarina, sul do Brasil. Biotemas, 14(2): 109-140.

HADLICH, R.M. 1983. Contribuição ao levantamento taxonômico das algas marinhas bentônicas do mangue de Itacorubi. Trabalho de Conclusão de Curso. Curso de Graduação em Ciências Biológicas da Universidade Federal de Santa Catarina, Florianópolis, Brasil. 1v.

HADLICH, R.M. 1984. Contribuição ao levantamento taxonômico das algas marinhas bentônicas do mangue de Itacorubi - Florianópolis - Ilha de Santa Catarina - Brasil: I Chlorophyta. Insula, 14: 121-138.

HADLICH, R.M. \& BOUZON, Z.L. 1985. Contribuição ao levantamento taxonômico das algas marinhas bentônicas do mangue de Itacorubi - Florianópolis - Ilha de Santa Catarina Brasil: II - Rhodophyta. Insula, 15: 89-116.

HANSEL, F.A. 2000. Análise de biomarcadores lipídicos em sedimentos de manguezais. Dissertação de Mestrado. Programa de Pós Graduação de Química da Universidade Federal de Santa Catarina, Florianópolis, Brasil. 94p.

HASS, S.; PERSICH, G.; PORTO-FILHO, E.; SORIANOSIERRA, E.J.; SIERRA DE LEDO, B. \& GRÉ, J.C.R. 1989. Características ecológicas de biótopos com ocorrência de formas juvenis de mugilídeos. Pp: 35-35. In: Anais do Seminário sobre mugilídeos da costa brasileira. São Paulo, SP. 1v. 
HOSTIM-SILVA, M.; RIBEIRO, G.C.; CLEZAR, L. \& SIERRA DE LEDO, B. 1998. Abundância relativa e distribuição espaçotemporal de Micropogonias furnieri (Desmarest) e Cynoscion leiarchus (Cuvier) (Perciformes, Sciaenidae) no Manguezal de Itacorubí, Santa Catarina, Brasil. Pp. 247-258. In: E.J. SorianoSierra \& B. Sierra de Ledo (eds.). Ecologia e Gerenciamento do Manguezal de Itacorubí. NEMAR/CCB/UFSC, SDM/FEPEMA, Florianópolis. 440p.

HUBER, M.V. 2004. Estudo comparativo de três projetos de restauração de áreas degradadas de manguezais da Grande Florianópolis, SC. Dissertação de Mestrado. Programa de Pós Graduação de Engenharia Ambiental da Universidade Federal de Santa Catarina, Florianópolis, Brasil. 273p.

IBGE (Instituto Brasileiro de Geografia e Estatística). 2008. Estimativas de População. http://www.ibge.gov.br/home/ estatistica/populacao/. (Acesso em 27/06/2009).

LABHIDRO (Laboratório de Hidrologia). Estação Meteorológica

- Campus Universitário da UFSC. http://www.labhidro.ufsc.br/ estacaoufsc.html. (Acesso em 03/07/2009).

LAUT, L.L.M.; SILVA, S.F.; BONETTI, C.; FIGUEIREDO JR., A.G. \& CRAPEZ, M.A.C. 2007. Foraminíferos e atividade bacteriana aplicados no diagnóstico ambiental do estuário do rio Itacorubí, Florianópolis, SC. Revista Brasileira de Geociências, 37(3): 565-578.

MASUTTI, M.B. \& PANITZ, C.M.N. 1999. O manguezal do Itacorubi como barreira biogeoquímica: Estudo de caso. Dissertação de Mestrado. Programa de Pós Graduação de Engenharia Ambiental da Universidade Federal de Santa Catarina, Florianópolis, Brasil. 196p.

MASUTTI, M.B. \& PANITZ, C.M.N. 2000. Chasmagnathus granulata and Spartina alterniflora contribution to metal cycling in Itacorubi mangrove (Santa Catarina Island, South Brazil). Pp: 51. In: Anais do Seminário Internacional Represa do Lobo-Broa 30 anos de Pesquisa em Limnologia, Gerenciamento e Participação da Comunidade e Bases Científicas para o Gerenciamento da Eutrofização. São Carlos, SP. 1v.

MASUTTI, M.B.; PANITZ, C.M.N. \& PEREIRA, N.C. 2000. Biodisponibilidade e Bioconcentração de Metais-traço no Manguezal do Itacorubi (Florianópolis - SC). Pp. 207-219. In: E.J.G. Espíndola, C.M. Paschoal, O. Rocha, M.B. Bohrer \& A.L. Oliveira Neto (eds.). Ecotoxicologia - Perspectivas para o Século XXI. RiMa, São Carlos. 564p.

MASUTTI, M.B.; PANITZ, C.M.N.; PEREIRA, N.C.; TESTA, C.; TORRES, M.; TRIBBES, T. \& WILHELM FILHO, D. 1998. Metais pesados e alterações nas defesas antioxidantes no marisco-do-mangue (Mytella guianensis) como indicadores da contaminação do manguezal do Itacorubi (Florianópolis - SC). Pp: 255-257. In: Anais da XI Semana Nacional de Oceanografia. Rio Grande, RS. 709p.

MATER, L.; ALEXANDRE, M.R.; HANSEL, F.A. \& MADUREIRA, L.A.S. 2004. Assessment of Lipid Compounds and Phosphorus in Mangrove Sediments of Santa Catarina Island, SC, Brazil. Journal of Brazilian Chemical Society, 5(15): 725734.

MENEGOTTO, F.M. 2008. Jacaré no asfalto. O Eco. http://www. oeco.com.br/preview/37-reportagens/2169-oeco_25950. (Acesso em 15/06/2009).

MORAES, C.M.; QUEIRÓZ, R.R.U.; SOUZA, I.G.; SIERRA DE LEDO, B. \& SORIANO-SIERRA, E.J. 1998. O manguezal de Itacorubí: Estudo da distribuição das espécies de ferro. Pp. 103-114. In: E.J. Soriano-Sierra \& B. Sierra de Ledo (eds.). Ecologia e Gerenciamento do Manguezal de Itacorubí. NEMAR/ CCB/UFSC, SDM/FEPEMA, Florianópolis. 440p.

NAKA, L.N. \& RODRIGUES, M. 2000. As aves da Ilha de Santa Catarina. Editora da UFSC, Florianópolis. 294p.

NASCIMENTO, M.V. 1989. Os manguezais da Ilha de Santa Catarina. Pp: 287-294. In: Anais do $2^{\circ}$ Encontro Nacional sobre Meio Ambiente. Florianópolis, SC. 294p.

OLIVEIRA, C.P.L. \& PANITZ, C.M.N. 2003. Evolutionary aspects of Itacorubi Mangrove identified with photo interpretation and field surveys. http://www.cartografia.cl/download/cesarlopes. pdf. (Acesso em 05/05/2009).

OLIVEIRA, C.R. 2006. Avaliação da biodegradação de Pireno pela microbiota nativa em sedimento do Manguezal do Itacorubi, Florianópolis, SC. Dissertação de Mestrado. Programa de Pós Graduação de Química da Universidade Federal de Santa Catarina, Florianópolis, Brasil. 56p.

PAGLIOSA, P.R. 2004. Variação espacial nas características das águas, dos sedimentos e da macrofauna bêntica em áreas urbanas e em unidades de conservação na Baía da Ilha de Santa Catarina. Tese de Doutorado, Universidade Federal de São Carlos, São Paulo, Brasil. 100p.

PAGLIOSA, P.R.; FONSECA, A.; BOSQUILHA, G.B.; BRAGA, E.S. \& BARBOSA, F.A.R. 2005. Phosphorus dynamics in water and sediments in urbanized and non-urbanized rivers in Southern Brazil. Marine Pollution Bulletin, 50: 965-974.

PANITZ, C.M.N. 1986. Produção e decomposição de serapilheira no mangue do Rio Itacorubi, Ilha de Santa Catarina, Florianópolis, Brasil. Tese de Doutorado. Programa de Pós 
Graduação de Ecologia e Recursos Naturais da Universidade Federal de São Carlos, São Carlos, Brasil. 601p.

PANITZ, C.M.N. 1987a. Perfil funcional da gramínea Spartina alterniflora no mangue do rio Itacorubi, Ilha de Santa Catarina, Florianópolis, Brasil (2735'S-48³1'W). Publicações Academia Ciências, 54(1): 100-116.

PANITZ, C.M.N. 1987b. Variação Estacional da Biomassa de $S$. alterniflora no Manguezal do Itacorubi, Florianópolis, SC. In: Anais do I Seminário de Ciências do Mar. Florianópolis, SC. 1v.

PANITZ, C.M.N. 1989. Spartina alterniflora como fonte potencial de matéria orgânica no manguezal do Rio Itacorubi, Ilha de Santa Catarina (Florianópolis, Brasil). Pp: 119-129. In: Anais do II Seminário sobre Ciências do Mar. Florianópolis, SC. 1v.

PANITZ, C.M.N. 1990. Valor Nutritivo do Folhedo da Vegetação do Manguezal do Itacorubi, Santa Catarina, Brasil. In: Anais do III Simpósio Nacional de Limnologia. Porto Alegre, RS. (CDROM).

PANITZ, C.M.N. 1992. Ecological aspects of a saltmarsh ecosystem in Santa Catarina Island, Brazil. Pp. 213-230. In: U. Seeliger (ed.). Coastal Plant Communities of Latin America. Academic Press, San Diego. 392 p.

PANITZ, C.M.N. 1993. Manguezais de Santa Catarina (Limite Austral): Estrutura, função e manejo. Trabalho do Concurso Público para Professor Titular da Universidade Federal de Santa Catarina, Florianópolis, Brasil. 173p.

PANITZ, C.M.N. 1997a. Ecological description of the Itacorubi mangrove, Ilha de Santa Catarina, Brazil. Pp. 204-225. In: B.L. Kjerfve, L.D. Lacerda \& S. Diop (eds.). Mangrove Ecosystem Studies in Latin America and Africa. UNESCO, Paris. 349p.

PANITZ, C.M.N. 1997b. Principais tensores no manguezal do rio Itacorubi, Florianópolis, SC. Pp: 360. In: Anais do VI Congresso Brasileiro de Limnologia. São Carlos, SP. 2v.

PANITZ, C.M.N. 1999a. Characterization of Itacorubi's mangrove phenology (Island of Santa Catarina, South Brazil). Pp: 528. In: Anais do XVI International Botanical Congress. Missouri, EUA. $1 \mathrm{v}$.

PANITZ, C.M.N. 1999b. Thematic mapping and vegetation classification of Itacorubi mangrove, Santa Catarina Island, south Brasil, using Remote Sensing and System of Geographic Information. Pp: 71. In: Anais do International conference on Sustainable Management of Coastal Ecosystems. Porto, Portugal. $1 \mathrm{v}$.

PANITZ, C.M.N. \& MASUTTI, M.B. 2000a. Contribuição, variação temporal e bioacumulação de metais pesados em
Spartina alterniflora no manguezal do Itacorubi. Pp: 15. In: Anais do V Simpósio de Ecossistemas Brasileiros. Vitória, ES. 328p.

PANITZ, C.M.N. \& MASUTTI, M.B. 2000b. O impacto do lixão desativado para o manguezal do Itacorubi, Florianópolis, SC. Pp: 303-310. In: Anais do V Simpósio de Ecossistemas Brasileiros. Vitória, ES. 328p.

PANITZ, C.M.N. \& MASUTTI, M.B. 2000c. Variação temporal no teor de metais traço e contribuição anual da Biomassa de Spartina alterniflora (Loiseleur, 1807), para a ciclagem de metais no manguezal do Itacorubi, Florianópolis, SC. Pp: 311-318. In: Anais do V Simpósio de Ecossistemas Brasileiros. Vitória, ES. $328 \mathrm{p}$.

PONTES, J.M. 2007. A eficácia do Termo de Ajustamento de Conduta como instrumento de tutela ambiental: o caso do Shopping Iguatemi (Florianópolis/SC). Trabalho de Conclusão de Curso. Curso de Graduação em Direito da Universidade Federal de Santa Catarina, Florianópolis, Brasil. 118p.

PORTO-FILHO, E. \& PANITZ, C.M.N. 2000. Operação resgate da flora e fauna da área do Manguezal do Itacorubi, afetada pela obra do Elevado do CIC, Florianópolis, SC. UFSC, Florianópolis. $1 \mathrm{v}$.

PMF (Prefeitura Municipal de Florianópolis). 2000. Agenda 21 local do município de Florianópolis: meio ambiente quem faz é a gente. Prefeitura Municipal, Florianópolis. 244p.

PMF (Prefeitura Municipal de Florianópolis). 2002. Decreto Municipal $n^{\circ} 1529,8$ de julho de 2002. Prefeitura Municipal de Florianópolis, Brasil.

QUEIROZ, R.U.; SIERRA DE LEDO, B. \& SORIANOSIERRA, E.J. 1998a. Ocorrência e ciclagem de metais pesados no Manguezal de Itacorubí, SC, Brasil. Pp. 313-322. In: E.J. SorianoSierra \& B. Sierra de Ledo (eds.). Ecologia e Gerenciamento do Manguezal de Itacorubí. NEMAR/CCB/UFSC, SDM/FEPEMA, Florianópolis. 440p.

QUEIROZ, R.U.; SIERRA DE LEDO, B.; SORIANO-SIERRA, E.J.; DUTRA, S.J. \& HASS, P. 1998b. Observations of metallic elements transportation in estuarine environment. Pp. 323-328. In: E.J. Soriano-Sierra \& B. Sierra de Ledo (eds.). Ecologia e Gerenciamento do Manguezal de Itacorubí. NEMAR/CCB/ UFSC, SDM/FEPEMA, Florianópolis. 440p.

RAUEN, T.G.; DEBACHER, N.A. \& SOUZA-SIERRA, M.M. 2002. Tensoatividade de ácidos húmicos de procedências distintas. Química Nova, 25(6): 909-913.

RIBEIRO, G.C.; CLEZAR, L. \& HOSTIM-SILVA, M. 1988. Aspectos ecológicos da tainha (Perciformes-Mugilidae) no Manguezal do Itacorubi, Florianópolis/SC, Brasil. Pp: 410. In: 
Anais do XV Congresso Brasileiro de Zoologia. Curitiba, PR. $1 \mathrm{v}$.

RIBEIRO, G.C.; CLEZAR, L. \& HOSTIM-SILVA, M. 1989. Bioecologia de Mugilidae e ictiofauna acompanhante na Ilha de Santa Catarina, SC, Brasil. Considerações preliminares. Pp: 57. In: Anais do XVI Congresso Brasileiro de Zoologia. João Pessoa, PB. 1v.

RIBEIRO, G.C.; CLEZAR, L.; HOSTIM-SILVA, M. \& SIERRA DE LEDO, B. 1998. Ocorrência e abundância e distribuição de jovens de Mugilidae no Manguezal de Itacorubí, SC, Brasil. Pp. 259-268. In: E.J. Soriano-Sierra \& B. Sierra de Ledo (eds.). Ecologia e Gerenciamento do Manguezal de Itacorubí. NEMAR/ CCB/UFSC, SDM/FEPEMA, Florianópolis. 440p.

RIBEIRO, S. 1999. Ocorrência e distribuição do "mariscodo-mangue" (Mytella falcata e Mytella guyanensis) na Ilha de Santa Catarina - SC. Trabalho de Conclusão de Curso. Curso de Graduação em Ciências Biológicas da Universidade Federal de Santa Catarina, Florianópolis, Brasil. 70p.

RIVAIL DA SILVA, M.; LAMOTTE, M.; DONARD, O.F.X.; SORIANO-SIERRA, E.J. \& ROBERT, M. 1998. Contaminação por metais presentes em sedimentos de superfície de mangues, lagoas e da Baía Sul na Ilha de Santa Catarina. Pp. 337-360. In: E.J. Soriano-Sierra \& B. Sierra de Ledo (eds.). Ecologia e Gerenciamento do Manguezal de Itacorubí. NEMAR/CCB/ UFSC, SDM/FEPEMA, Florianópolis. 440p.

SÁNCHEZ DALOTTO, R.A. 2003. Estruturação de dados como suporte à gestão de manguezais utilizando técnicas de geoprocessamento. Tese de Doutorado. Programa de Pós Graduação de Engenharia Civil da Universidade Federal de Santa Catarina, Florianópolis, Brasil. 242p.

SANTOS, L.P.S. 2007. Caracterização da variabilidade hidroquímica dos estuários dos rios Itacorubi e do Sertão, Florianópolis (SC). Trabalho de Conclusão de Curso. Curso de Graduação em Geografia da Universidade Federal de Santa Catarina, Florianópolis, Brasil. 53p.

SCHMITZ, H.J. 2004. Estudo de uma assembléia de drosofilideos do manguezal do Itacorubi, ilha de Santa Catarina, Brasil. Trabalho de Conclusão de Curso. Curso de Graduação em Ciências Biológicas da Universidade Federal de Santa Catarina, Florianópolis, Brasil. 69p.

SCHMITZ, H.J.; VALENTE, V.L.S. \& HOFMANN, P.R.P. 2007. Taxonomic survey of Drosophilidae (Diptera) from mangrove forests of Santa Catarina Island, Southern Brazil. Neotropical Entomology, 36(1): 53-64.
SICK, H.; AZEVEDO, T.R. \& BEGE, L.A.R. 1979. Lista preliminar das aves do estado de Santa Catarina. Checklist. FATMA, Florianópolis, SC. 1v.

SICK, H.; BEGE, L.A.R.; AZEVEDO, T.R. 1981. Aves do estado de Santa Catarina - lista sistemática baseada em bibliografia, material de museu e observação de campo. Sellowia Zoologia, 1: 7-51.

SIERRA DE LEDO, B. \& SORIANO-SIERRA, E.J. 1998a. Contribución para el manejo integrado de sistemas estuarinos y sus recursos em la Isla de Santa Catarina, Brasil. Pp. 379-388. In: E.J. Soriano-Sierra \& B. Sierra de Ledo (eds.). Ecologia e Gerenciamento do Manguezal de Itacorubí. NEMAR/CCB/ UFSC, SDM/FEPEMA, Florianópolis, SC. 440p.

SIERRADE LEDO, B. \& SORIANO-SIERRA, E.J. 1998b. Fontes de energia auxiliar no ecossistema do Manguezal de Itacorubi, Ilha de Santa Catarina, Brasil. Pp. 13-30. In: E.J. SorianoSierra \& B. Sierra de Ledo (eds.). Ecologia e Gerenciamento do Manguezal de Itacorubí. NEMAR/CCB/UFSC, SDM/FEPEMA, Florianópolis. 440p.

SIERRA DE LEDO, B. \& SORIANO-SIERRA, E.J. 1998c. Utilisation economique d'ecossistèmes fragiles: un defi pour la gestion integrée dans la zone côtière soustropicale du Brésil. Pp. 389-398. In: E.J. Soriano-Sierra \& B. Sierra de Ledo (eds.). Ecologia e Gerenciamento do Manguezal de Itacorubí. NEMAR/ CCB/UFSC, SDM/FEPEMA, Florianópolis. 440p.

SIERRA DE LEDO, B.; SORIANO-SIERRA, E.J. \& QUEIROZ, R.U. 1998. Pathways of metallic elements between structural components of a mangrove ecosystem in the southern region of Brazil. Pp. 329-336. In: E.J. Soriano-Sierra \& B. Sierra de Ledo (eds.). Ecologia e Gerenciamento do Manguezal de Itacorubí. NEMAR/CCB/UFSC, SDM/FEPEMA, Florianópolis. 440p.

SILVA, F.S.; LAUT, V.M.; LAUT, L.L.M.; FIGUEIREDO JR., A. G.; BONETTI, C.; VIANA, L.G. \& CRAPEZ, M.A.C. 2005. Avaliação da qualidade ambiental em sedimentos superficiais do estuário do Itacorubi, Baía Norte (SC), utilizando a relação granulometria e atividade respiratória bacteriana. Pp: 1-3. In: Anais do X Congresso da Associação Brasileira de Estudos Quaternários. Guarapari, ES. 1v.

SORIANO-SIERRA, E.J. 1993. Caracterização ecológica dos biótopos e sua ocupação pelas comunidades vegetais no Manguezal de Itacorubi (Ilha de Santa Catarina, SC, Brasil). Trabalho do Concurso Público para Professor Adjunto da Universidade Federal de Santa Catarina, Florianópolis, Brasil. $124 \mathrm{p}$. 
SORIANO-SIERRA, E.J. 1998a. Estrutura do mosaico ambiental no Manguezal de Itacorubí, Ilha de Santa Catarina, Brasil. Pp. 4778. In: E.J. Soriano-Sierra \& B. Sierra de Ledo (eds.). Ecologia e Gerenciamento do Manguezal de Itacorubí. NEMAR/CCB/ UFSC, SDM/FEPEMA, Florianópolis. 440p.

SORIANO-SIERRA, E.J. 1998b. Fluxos de maré e interferências antropogênicas à hidrodinâmica, no espaço funcional de um Manguezal naturalmente estressado. Pp. 269-288. In: E.J. SorianoSierra \& B. Sierra de Ledo (eds.). Ecologia e Gerenciamento do Manguezal de Itacorubí. NEMAR/CCB/UFSC, SDM/FEPEMA, Florianópolis. 440p.

SORIANO-SIERRA, E.J. \& SIERRA DE LEDO, B. 1998. Man-made nutrient enrichment in a mangrove system of Santa Catarina Island, Brazil: Problems and proposal for restoration. Pp. 361-368. In: E.J. Soriano-Sierra \& B. Sierra de Ledo (eds.). Ecologia e Gerenciamento do Manguezal de Itacorubí. NEMAR/ CCB/UFSC, SDM/FEPEMA, Florianópolis. 440p.

SORIANO-SIERRA, E.J.; DE LA CORTE, F.S.; SIMONASSI, J.C. \& SOUZA-SIERRA, M.M.; 1998a. Caracterização hidrológica do manguezal de Itacorubí e intercâmbios de água e matérias particuladas e dissolvidas entre o ecossistema e a Baía Norte adjacente. Pp. 289-312. In: E.J. Soriano-Sierra \& B. Sierra de Ledo (eds.). Ecologia e Gerenciamento do Manguezal de Itacorubí. NEMAR/CCB/UFSC, SDM/FEPEMA, Florianópolis. 440 p.

SORIANO-SIERRA, E.J.; MACEDO-SILVA, J.R.B.; DERNER, R.B. \& BRANCO, J.O. 1998b. Aspectos ecológicos do Manguezal de Itacorubí, Santa Catarina, Brasil. Pp. 115-138. In: E.J. SorianoSierra \& B. Sierra de Ledo (eds.). Ecologia e Gerenciamento do Manguezal de Itacorubí. NEMAR/CCB/UFSC, SDM/FEPEMA, Florianópolis. 440p.

SORIANO-SIERRA, E.J.; NUNES, L.C.; MACEDO-SILVA, J.R.B.; DERNER, R.B. 1983. Estructura del manglar del Rio Itacorubí en la Isla de Santa Catarina, Brasil. Pp: 101-103. In: Anais do $2^{\circ}$ Simposium Latinoamericano de la Oceanografia Biológica. Montevidéu, Uruguai. 1v.

SORIANO-SIERRA, E.J.; SIERRA DE LEDO, B. \& QUEIROZ, R.U. 1998c. Ecological costs of urban expansion in a mangrove ecosystem: A case study. Pp. 369-378. In: E.J. Soriano-Sierra \& B. Sierra de Ledo (eds.). Ecologia e Gerenciamento do Manguezal de Itacorubí. NEMAR/CCB/UFSC, SDM/FEPEMA, Florianópolis. 440p.

SOUZA, C.R. DE \& NAPOLEÃO, F. 2002.Diagnóstico ambiental da região da UDESC - Itacorubi. Trabalho de Conclusão de Curso. Curso de Graduação em Geografia da Universidade do Estado de Santa Catarina, Florianópolis, Brasil. 40p.
SOUZA-SIERRA, M.M.; GIOVANELA, M. \& VIEIRA, S.M. 1998. Composição elementar e propriedades espectroscópicas de compostos húmicos do Manguezal de Itacorubí, Ilha de Santa Catarina. Pp: 79-102. In: E.J. Soriano-Sierra \& B. Sierra de Ledo (eds.). Ecologia e Gerenciamento do Manguezal de Itacorubí. NEMAR/CCB/UFSC, SDM/FEPEMA, Florianópolis. 440p.

SOUZA-SOBRINHO, R.J.; BRESOLIN, A. \& KLEIN, R.M. 1969. Os manguezais na Ilha de Santa Catarina. Insula, 2: 1-21.

SPIVAK, E.D. 1997. Cangrejos estuariales del Atlántico sudoccidental $\left(25^{\circ}-41^{\circ} \mathrm{S}\right)$ (Crustácea: Decapoda: Brachyura). Investigaciones Marinas, 25: 105-120.

TORRES, M.A.; TESTA, C.P.; GÁSPARI, C.; MASUTTI, M.B.; PANITZ, C.M.N.; CURI-PEDROSA, R.; DE ALMEIDA, E.A.; MASCIO, P.D. \& WILHELM FILHO, D. 2002. Oxidative stress in the mussel Mytella guyanensis from polluted mangroves on Santa Catarina Island, Brazil. Marine Pollution Bulletin, 44: 923 932.

TRIBESS, T.; TORRES, M.A.; TESTA, C.P. \& WILHELM FILHO, D. 1998. Antioxidant defenses in the mangrove mussel Mytella guyanensis. Pp: 410-410. In: Anais da XIII Reunião anual da Federação de Sociedades de Biologia Experimental - FESBE. Caxambu, MG. 1v.

TRIERVEILER-PEREIRA, L.; BALTAZAR, J.M. \& LEITE, C.L. 2008a. Santa Catarina Island mangroves 1 - First report of Myxomycetes on Avicennia schaueriana. Mycotaxon, 103: 145152.

TRIERVEILER-PEREIRA, L.; BALTAZAR, J.M. \& LEITE, C.L. 2008b. Santa Catarina Island mangroves 2 - First report of Cytospora rhizophorae from Brazil. Mycotaxon, 104: 119-122.

TRIERVEILER-PEREIRA, L.; BALTAZAR, J.M. \& LEITE, C.L. 2009. Santa Catarina Island mangroves 4 - Xylophilous basidiomycetes. Mycotaxon, 109: 107-110.

TRIERVEILER-PEREIRA, L.; BALTAZAR, J.M.; SANTANA, M.C.; GERLACH, A.; BEKAI; L.H. \& LEITE, C.L. 2007. Diversidade de fungos xilófilos em três manguezais da Ilha de Santa Catarina, SC: Uma abordagem ecológica. Pp: 1-2. In: Anais do VIII Congresso de Ecologia do Brasil. Caxambu, MG. 1v.

TUNDISI, J.G. 2003. Água no século XXI: Enfrentando a escassez. Rima, São Carlos. 248p.

UNICOBI (União dos Conselhos Comunitários da Bacia do Rio Itacorubi). 2006. Plano Diretor de Florianópolis: Bacia do Itacorubi. Propostas e reivindicações das Assembléias para subsidiar a elaboração do novo Plano Diretor de Florianópolis. UNICOBI, Florianópolis. 10p. 
VIEIRA, A.L. 1987. Análise qualitativa e quantitativa do fitoplâncton do Manguezal do Itacorubi-Resultados preliminares. Trabalho de Conclusão de Curso. Curso de Graduação em Ciências Biológicas da Universidade Federal de Santa Catarina, Florianópolis, Brasil. 100p.

VIEIRA, S.J. 2007. Transdisciplinaridade aplicada à gestão ambiental de unidade de conservação. Estudo de caso: Manguezal do Itacorubi. Tese de Doutorado. Programa de Pós Graduação de Engenharia Civil da Universidade Federal de Santa Catarina, Florianópolis, Brasil. 292p.

WILHELM FILHO, D.; PANITZ, C.M.N. \& MASUTTI, M.B. 2000. Metals in Mytella guyanensis (Lamarck, 1891) from Itacorubi and Ratones Mangroves (Santa Catarina Island, Brazil). Pp: 6. In: Anais da Mangrove 2000, Sustentabilidade de estuários e manguezais: desafios e perspectivas. Recife, PE. $1 \mathrm{v}$.

ZANCHET, C.M. 1998. Uma proposta para um Parque urbano do manguezal do Itacorubi. Trabalho de Conclusão de Curso. Curso de Graduação em Arquitetura e Urbanismo da Universidade Federal de Santa Catarina, Florianópolis, Brasil. 15p.

Submetido em 11/12/2008.

Aceito em 10/09/2009. 